\title{
Guilty speculators? Range-based conditional volatility in a cross- section of wheat futures
}

\section{Journal Article}

Author(s):

Haase, Marco; Huss, Matthias

Publication date:

2018-06

Permanent link:

https://doi.org/10.3929/ethz-b-000313778

\section{Rights / license:}

Creative Commons Attribution-NonCommercial-NoDerivatives 4.0 International

\section{Originally published in:}

Journal of Commodity Markets 10, https://doi.org/10.1016/j.jcomm.2017.10.001 


\begin{abstract}
In response to the unusually high levels of price volatility during the world food price crisis of $2007 / 2008$, US and EU regulators have introduced position limits that aim to protect commodity markets from exposure to excess speculation. Such regulatory initiatives presuppose that excess speculation is indeed responsible for excess volatility. Our results debunk this presupposition and show the opposite effect: speculative activity reduces price volatility, particularly during times of distress. Our findings are based on a cross-section of wheat futures contracts, traded at five different commodity exchanges with various degrees of speculative activity. Volatility is estimated based on a Conditional Autoregressive Range Model (CARR), which is further augmented with exogenous excess-speculation shocks (CARRX). These models capture herding, feedback and noise trading, and a threshold version (TCARRX) identifies regimes in which the anatomy of the volatility process changes according to the level of excess speculation. Our findings support Working's hypothesis that a certain level of excess speculation is essential for a well-functioning market.
\end{abstract}

JEL Classification: C22,C24, G12, G13, G18, Q02, Q11

Key words: range based volatility, wheat futures, speculation 


\section{Introduction}

High volatility can have serious political ramifications. This is particularly the case in the context of agricultural commodities, where volatile prices may threaten food security and thereby cause social unrest (e.g., Bellemare, Barrett, and Just, 2013; Clapp, 2009; Gilbert and Morgan, 2010). Limiting food price volatility has therefore been defined as a key target in the United Nation's 2030 Agenda for Sustainable Development. ${ }^{1}$ In the mid-2000s, commodity-linked investment vehicles such as Commodity Traded Notes and Commodity Linked Notes gained massively in importance. From 2003 to 2008, the investment capital allocated to such indexed products increased by a factor of $20^{2}$. At the same time, commodity prices and volatilities rose to "unusually high" levels, which led to disputes whether the observed increase in volatilities was induced by the financialisation of commodity markets.

Public perception and the political debate seem to have reached their verdict: speculators, and here particularly index investors, have been pronounced guilty of sending volatilities to abnormally high levels. The regulatory response has been harsh. The U.S. Commodity Futures Trading Commission (CFTC) ${ }^{3}$ (in conjunction with the Dodd-Frank Wall Street Reform and Consumer Protection Act of 2010) as well as the European Securities and Markets Authority (ESMA) developed new standards for establishing position limits. The wisdom of these recent decisions - and, as a consequence, the effectiveness of the resulting regulations - clearly hinges on the assumption that speculators are indeed responsible for all negative external effects.

The academic jury is, however, still out on this question. This paper contributes to the discussion

\footnotetext{
${ }^{1}$ On paragraph 2.c the UN sets a volatility goal: "Adopt measures to ensure the proper functioning of food commodity markets and their derivatives and facilitate timely access to market information, including on food reserves, in order to help limit extreme food price volatility", see United Nations (2015), page 13.

${ }^{2}$ Masters (2008) estimates the total value of commodity-index linked investments to USD 13 bn at the end of 2003 , which has increased to more than USD 260 bn as of March 2008, see Masters (2008), page 3.

${ }^{3}$ Federal Register (2016), page 96716

${ }^{4}$ Directive 2014/65/EU and Regulation (EU) No 600/2014 (MiFID II and MiFIR)
} 
by analysing how conditional volatilities in markets for agricultural commodity futures have changed in the post-financialisation period. We focus on a cross-section of markets for wheat futures for which sufficient time-series data are available to analyse the behaviour of volatilities over time. Our choice of this empirical setting is motivated by the fact that the "anatomy" of conditional volatilities depends on many factors other than speculation, and that many of these are commodity-specific (for agricultural commodities, they include weather conditions and bad harvests). We acknowledge that even wheat futures traded at different exchanges are not perfectly identical: exchanges differ in terms of trading volume, liquidity costs and many other factors. Still, focusing on a set of relatively homogenous futures allows us to isolate speculation-induced effects more precisely.

Specifically, we analyse wheat futures traded in Chicago, Kansas, Minneapolis, Paris and London $^{5}$. These wheat contracts have been differentially exposed to the inflow of capital to index investments. The Chicago wheat contract has always been a substantial part of virtually all major indices. Taking the three major indices, the S\&P Goldman Sachs Commodity Index (GSCI), the Bloomberg Commodity Index (BCOM) and the Rogers International Commodity Index (RICI) as an example, Chicago wheat weights range between $3.8 \%$ (GSCI), $4.8 \%$ (BCOM) and $7 \%$ (RICI) in 2005 and between $3.5 \%, 3.8 \%$ and $4.8 \%$ in 2015 , respectively ${ }^{6}$. The Kansas wheat contract has a shorter tradition of being included in the major index investments ${ }^{7}$ and accounts for a more moderate part of the asset allocation, with a typical weight of approximately $1 \%$ in $2015^{8}$.

Minneapolis wheat and the two European wheat contracts included here (Milling Wheat No. 2, Feed Wheat) are, by contrast, relatively illiquid and are therefore excluded from the investment scheme in all major index guidelines. These particular characteristics make our selection of data

\footnotetext{
${ }^{5}$ Some of these contracts are seen as close substitutes in hedging contexts and may even be considered substitutes in some physical production processes.

${ }^{6}$ The weights are taken form the respective Index Guide Manuals.

${ }^{7} \mathrm{RICI}$ includes $1 \%$ of Kansas wheat (KW) in 2010 and the BCOM 1.3\% in 2013, while the S\&P GSCI holds $1.4 \%$ of $\mathrm{KW}$ in 2005.

${ }^{8}$ The only exception is GSCI, which has an index weight of $1 \%$ in 2005.
} 
an ideal empirical setting for studying the effects of capital inflow on commodity-related index investments.

For each of these markets, we estimate a Conditional Autoregressive Range (CARR) model. The CARR model is an informationally more efficient alternative to a standard Generalised Autoregressive Conditional Heteroscedasticity (GARCH) model. Andersen and Bollerslev (1998), for example, estimate that the precision of a single-day range estimator is equivalent to that of a standard return-based estimator with a sampling frequency of 2-3 hours. We are particularly interested in the ARCH parameter of the model because it has a special interpretation in our context. The parameter measures the transmission of short-term shocks from one period to the next. If speculators really amplify volatility, due to herding behavior or feedback-trading, this should be reflected in cross-sectional differences: a higher value of the parameter would be expected in markets that are characterised by more speculative activity.

Our results point in the opposite direction, supporting the hypothesis that speculative activity reduces short-term shock transmission, either by improving the incorporation of new information and/or by reducing liquidity costs of trading. Over an observation period of approximately 20 years, we find the lowest shock amplification parameter for Chicago Wheat, the market with the highest exposure to speculative capital. Splitting the sample into sub-periods, we further find that the shock amplification parameter remained unchanged for Chicago Wheat although speculative activity substantially increased over time. By contrast, shock amplification decreased for Kansas Wheat over the second half of our observation period, a time when index speculation gained massively in importance. The opposite is observed for the wheat contracts that are not even part of any index allocation. These findings are consistent with the traditional view that speculation dampens volatility.

We further augment the model with innovations of the Working T-Index, the standard measure 
of excess speculation. This setup allows a more direct test of speculation-induced volatility: the effect parameter of innovations in the Working T-Index measures the contemporaneous impact of speculative trading on period-by-period volatility. A positive sign is expected if speculation increases volatility through noise trading. We therefore term this parameter the guilt parameter. However, we find a significant negative effect of speculation on conditional volatility for Chicago and Kansas wheat. The guilt parameter for Minneapolis wheat is also negative but not significant. These results suggest that an increase in speculation dampens volatility, at least in markets where index investing takes place. Again, we observe that the dampening effect is stronger in more recent years. We also observe that our results are more pronounced when speculation is measured by information taken from the Commodity Index Traders (CIT) supplement report of the CFTC, which allows more precise identification of financial speculators than the information from the standard Commitments of Traders (COT) report of the CFTC ${ }^{9}$. This observation gives additional confidence to our results.

Finally, we estimate a threshold model to identify different regimes in the volatility process. For all commodities, we find that conditional volatility, shock amplification and the value of the guilt parameter are substantially higher in a low-speculation regime. However, if the level of speculation is sufficiently high, the parameter estimates converge to similar values in all markets, regardless of their typical level of liquidity. Hence, our results corroborate the argument originally formulated by Working (1960) that sufficient excess speculation is a necessary condition for a market to function well.

Our results have important implications for traders, exchanges and regulators alike. In order to confine volatility, an exchange should try to encourage at least a certain amount of excess speculation, which helps limiting trading costs. Regulators should proceed with great caution when they consider introducing position limits because such limits may actually amplify the erratic volatility

\footnotetext{
${ }^{9}$ Sanders and Irwin (2010) argue that CIT data "are an improvement over the more heavily aggregated traditional COT classifications, and they should provide a good, albeit imperfect, measure of index trader activity."
} 
patterns they are meant to reduce.

However, our results also suggest that the dampening effect that can be attributed to speculation is rather small. This observation is consistent with the view that the influence of speculators on volatility is mainly due to reduced transaction cost (e.g., see Marshall, Nguyen, and Visaltanachoti, 2011).

The rest of the paper is organized as follows, Section 2 provides a short description of the history of position limits, a literature discussion, the theoretical background and a description of the empirical setup. Section 3 describes the data we used for the empirical estimation. Section 4 provides the estimation results for our standard CARR model as well as for the CARRX model. In section 5 we discuss the exogenous threshold model and report the estimation results. Section 6 concludes.

\section{Background and previous research}

\subsection{Position limits}

Position limits define the maximum number of contracts a person may hold or control. The implementation of position limits pursues three complementary objectives: protecting clearing, preventing markets from exposure to manipulation and excess speculation, and reducing the risk of price distortions ${ }^{10}$.

Position limits have been in place since 1938, after the US Congress passed the Commodity Exchange Act (CEA) in 1936 to amend the Grain Futures Act established in 1922. The CEA authorised the Commodity Exchange Commission (CEC; the predecessor of the CFTC that took over in 1974) to implement "federal position limits" upon determining that they are necessary and

\footnotetext{
${ }^{10}$ Section $4 \mathrm{a}(\mathrm{a})$ of the CEA, 7 USC $6 \mathrm{a}(\mathrm{a})$, specifically holds that excessive speculation in a commodity traded for future delivery may cause "sudden or unreasonable fluctuations or unwarranted changes in the price of such commodity."
} 
appropriate. At that time, the CEC imposed limits on wheat, corn, oats, barley, flaxseed, grain sorghums and rey. Subsequently, more and more commodities were included whenever Congress amended the act. Since 1981, the CTFC required exchanges to establish speculative position limits ("accountability limits") for all commodities, which are not subject to federal limits ${ }^{11}$.

The Dodd-Frank Act of 2010 marked major change in regulatory practice. The CFTC expanded their rules to include OTC derivatives, and modified aggregation rules ${ }^{12}$. Furthermore, the CFTC interpreted the act as a mandate to develop position limits for all 28 core commodities, regardless of any evidence on the necessity and appropriateness of such limits ${ }^{13}$. The new set of rules was vacated in court in $2012^{14}$. The court remanded the matter to the CFTC, which issued a supplementary proposal in May 2016. The CFTC deferred action on three "cash-settled" futures, but "finds it necessary to implement position limits as a prophylactic measure for the 25 core referenced futures contracts", so the rules remain in place ${ }^{15}$.

Following this reasoning, the European Commission asked the European Securities and Markets Authority (ESMA) to develop even stricter rules. Steven Maijoor, the chair of the ESMA proudly announced in 2015 that the "EU is going into new, unchartered territory by implementing the most extensive position limits regime in the world"16.

\subsection{Economic effects of speculation}

While there is a growing literature on speculation-induced volatility, research on the economic effects of speculation is still inconclusive. Overall, studies which found evidence for destabilizing effects balance out studies which find the opposite. This general result is independent of the methodologies

\footnotetext{
${ }^{11}$ CFTC regulation 150.5 .

${ }^{12}$ see Federal Register (2011).

${ }^{13}$ See ISDA vs. CFTC (2012), page 10.

${ }^{14}$ The courts decision states that "the CFTC's error in this case was that it fundamentally misunderstood and failed to recognize the ambiguities in the statute", and "it would be far more disruptive if the Position Limits Rule were allowed to go into effect while on remand." See ISDA vs. CFTC (2012), page 42.

${ }^{15}$ See, Federal Register (2016), page 96716.

${ }^{16}$ MIFID/MIFR - CSD hearing before ECON, 24 March 2015 (ESMA/2015/620).
} 
used, time periods analysed or commodities analysed ${ }^{17}$.

Granger Causality (GC) tests are by far the most applied empirical methods in this context. Studies that found speculation-induced destabilisation effects include Roache (2010), Hernandez and Torero (2010) and Gilbert and Pfuderer (2014). Stabilisation effects were found by Sanders and Irwin (2011), Irwin and Sanders (2012) and Aulerich, Irwin, and Garcia (2013). However, GC-tests have often been criticised because they only account for a lead lag-variable relationship between post-trading and future price variability and ignore possible simultaneous effects. Grosche (2014) explicitly focuses on the interpretation of GC tests of speculation-induced price effects in agricultural commodity markets and questions the usefulness of GC tests in this context.

Other empirical tests are based on conditional volatility models, mainly the family of generalized autoregressive conditional heteroscedasticity (GARCH) models, developed by Engle (1982) and Bollerslev (1986), and their applications ${ }^{18}$. Speculation-induced destabilisation effects were found by Gilbert and Morgan (2010), Ji and Fan (2012), Roache (2010). Stabilisation effects were found by Bohl and Stephan (2013) and Kim (2015). Mixed effects were found by Gilbert (2012), who used GC tests as well as GARCH.

Other studies investigate the impact of speculative activity on co-movements of commodity markets and financial markets, using dynamic conditional correlation models (DCC; these are based on multivariate GARCH models ${ }^{19}$. Negative financialisation effects were found, for example, by Nazlioglu, Erdem, and Soytas (2013), Creti, Joëts, and Mignon (2013) and Bruno, Büyükşahin, and Robe (2016). Mixed results were found by Silvennoinen and Thorp (2013).

However, one communality across the majority of all studies is that volatility is measured by futures returns or squared futures returns. Our study differs fundamentally from this literature by

\footnotetext{
${ }^{17}$ For a comprehensive overview of the literature, see Cheng and Xiong (2014), Grosche (2014) or Haase, Zimmermann, and Zimmermann (2016))

${ }^{18}$ Chkili, Hammoudeh, and Nguyen (2014) provides a broad set of GARCH-type models with respect to their to forecast efficiency of commodity price volatility.

${ }^{19}$ The DCC model was introduced by Engle (2002).
} 
using an alternative measure of volatility, and complements it, by analysing the economic effects of feedback trading and noise trading on conditional volatility in regimes of low and high excess speculation across wheat markets.

\subsection{Speculation and volatility}

The traditional view of speculation is that it dampens volatility. There are two main arguments for this. The first argument is that speculators provide hedgers with highly desired liquidity and thereby lower trading cost (e.g., search cost for finding an adequate counterparty, volume-induced price movements $)^{20}$. The second argument is that speculators can increase the information efficiency of the market. Proponents of this view (e.g., Friedman, 1953; Working, 1960) argue that speculators can only be successful in the long run if they are able to make informed predictions about future supply and demand and hence about prospective prices. Such "skilled" speculators should smooth the price process, buying when prices are low and selling when prices are high. The opposite view argues that speculators are prone to herding behaviour and other types of positive-feedback strategies (e.g., De Long, Shleifer, Summers, and Waldmann, 1990; Shiller, Fischer, and Friedman, 1984; Shleifer and Summers, 1990). Such "unskilled" speculators should add momentum to the market, buying when prices are rising and selling when prices are falling, which would cause volatilities to increase.

As Working (1960) noted, markets are by their nature never black or white. Rather, skilled and unskilled speculation may simultaneously coexist in a market. In the long run, however, skilled speculation should restrain the fluctuations in the price movements that unskilled speculation tends to produce ${ }^{21}$. Thus, the central question here - whether speculators are guilty of causing high price volatility through their trading activity, or at least of amplifying it - requires an empirical answer.

\footnotetext{
${ }^{20}$ Pastor and Stambaugh (2003), for example, define market liquidity as "the ability to trade large quantities quickly, at low cost, and without moving the price".

${ }^{21}$ Others (e.g., Luo, 1998) show that, in equilibrium, unskilled speculators do not survive.
} 


\subsection{Empirical setup}

We are interested in analysing the dynamics of volatility. Our analysis is based on a variant of the ARCH/GARCH family of models developed by Engle (1982) and Bollerslev (1986). GARCH models are frequently used for modeling time series with autocorrelated conditional volatilities where large changes in prices tend to be followed by large changes, even when returns are serially uncorrelated. However, GARCH models are based on closing prices. Alizadeh, Brandt, and Diebold (2002) and Brandt and Jones (2006) have shown that this can make them inefficient because information about the variation between the closing prices is neglected. And since feedback and herding effects may well occur between closing prices, a standard GARCH model would pose a serious limitation to our analysis. Our analysis is therefore based on the range-based volatility estimator suggested by Parkinson (1980). Let $P_{\tau}$ be the price of an asset at time $\tau$. The price range over an interval [t-1, $\mathrm{t}]$, defined as

$$
R_{t}=\max \left\{\ln \left(P_{\tau}\right)\right\}-\min \left\{\ln \left(P_{\tau}\right)\right\}, \text { where } \quad \tau \in[t-1, t]
$$

is an unbiased estimator of volatility ${ }^{22}$ but incorporates more information than standard returnbased measures. Most importantly, it also captures the intra-period price spikes that return-based volatility measures ignore. In low-frequency contexts such as ours, this feature makes the price range a more efficient estimator of volatility than the price variance.

Based on this, Chou (2005) has developed a range-based extension of the standard GARCH approach, the Conditional Autoregressive Range (CARR) model. Although the CARR model was initially formulated as an autoregressive model, it can be modified to take additional explanatory variables into account (then termed CARRX). We use innovations of the Working T-Index, the

\footnotetext{
${ }^{22}$ The relationship between a price range and the estimate of a price variance $\hat{\sigma}_{P}^{2}$, given the price, follows a simple diffusion model without drift: $\hat{\sigma}_{P}^{2}=\frac{1}{4 \ln 2}\left(\ln H_{t}-\ln L_{t}\right)^{2}$.
} 
standard measure for excess speculation, as an exogenous variable. A CARRX model of order $(p, q, l)$ is given by:

$$
\begin{aligned}
R_{t} & =\lambda_{t} \varepsilon_{t}, \\
\lambda_{t} & =\omega+\sum_{i=1}^{p} \alpha_{i} R_{t-i}+\sum_{j=1}^{q} \beta_{j} \lambda_{t-j}+\sum_{k=1}^{l} \gamma_{k} X_{t, k},
\end{aligned}
$$

where $\lambda_{t}$ is the conditional mean of the range, based on all information up to time $t$, and $\epsilon_{t}$ is the shock to the range. The parameters $\omega, \alpha$ and $\beta$ characterise the inherent uncertainty in the range, the short-term impact effect, and the long-term effect of shocks to the range, respectively (with $\omega>0, \alpha_{i} \geq 0, \beta_{j} \geq 0$ and, if strict stationarity is assumed, $\sum \alpha_{i}+\sum \beta_{j}<1$ ). Exogenous variables, if included in the model are denoted by $X_{t, k}$. As we use innovations in the Working TIndex as exogenous variable, the parameter $\gamma$ measures the impact of changes in excess speculation on conditional volatility and is therefore our main measure to assess the "guilt" of speculators: if an increase in speculative activity leads to higher volatility, a positive sign is expected. We therefore refer to the parameter $\gamma$ as the guilt parameter. Following Alizadeh, Brandt, and Diebold (2002) and Brandt and Jones (2006), we assume that ranges are lognormally distributed. If the assumption holds, the model can be estimated by maximum likelihood with log-likelihood function

$$
\begin{aligned}
\ln L\left(\omega, \alpha, \beta, \gamma, \sigma, R_{t}\right)= & -\ln \left(R_{t}\right)-\frac{1}{2} \ln (2 \pi)-\frac{1}{2} \ln \left(\sigma^{2}\right) \\
& -\frac{1}{2} \frac{\left(\ln \left(R_{t}\right)-\ln (\lambda)+\sigma^{2} / 2\right)^{2}}{\sigma^{2}}
\end{aligned}
$$

where $\sigma^{2}$ denotes the variance of $\epsilon$.

Speculators may positively contribute to volatility by noise trading and by herding behavior. Noise trading affects the conditional volatility at the same moment as the trade occurs. Herding, on the other hand, is the result of a sequence of trades and affects conditional volatility only 
gradually (with a lag). In our specification, innovations of the T-Index therefore enter the equation unlagged. This has the consequence that the guilt parameter captures noise trading as well as intraperiod herding effects. Longer-term herding effects that spill over to the next period are captured by $\alpha$, which measures the period-to-period shock transmission. The parameter $\alpha$ has a special interpretation in the sample of wheat contracts of our empirical setup. Assuming that the processes governing conditional volatilities are comparable across wheat markets, cross-market differences in $\alpha$ should reflect cross-market differences in speculation-induced effects. If speculators indeed amplify next-period volatilities through herding or feedback trading, then $\alpha$ should be higher in those wheat markets where more speculation occurs. A lower $\alpha$, on the other hand, would indicate that market shocks are more efficiently incorporated in the prices of a specific commodity. We therefore refer to $\alpha$ as the shock amplification parameter.

Although the underlying commodity (wheat) is the same across the different contracts included in our study, the product the contract refer to is not identical. There are differences in end use, growing season, production regions and processes as well as in the institutional setting of the respective exchange. These differences may impact volatility clustering, and thus limit the comparability of $\gamma$ and $\alpha$ with respect to speculative effects to some extent. Since it only includes the T-index as an exogenous variable, Equation (2) implicitly assumes that there is no omitted variable bias. We will address this caveat by examining further exogenous variables (such as seasonal dummies, time to delivery and a proxy for inventory levels) in the robustness section B. In addition, we will provide a more direct test of the shock amplification parameter in which the level of excess speculation is used as an exogenous threshold variable. 


\section{Data}

We focus on five wheat contracts that are traded on different exchanges in the US and Europe: Chicago Wheat (CBOT), Kansas Wheat (KCBT), Minneapolis Wheat (MGEX), Paris Milling Wheat No. 2 (LIFFE) and London Feed Wheat (ICE). The analysis of this cross-section allows us to observe the impact of speculation on conditional volatility particularly precisely because the underlying good is more - although not perfectly - homogenous across these five contracts than across different kinds of commodities. At the same time this particular set of contracts is selected because there is substantial heterogeneity in their exposure to index speculation: whilst Chicago is subject to significant index speculation, Minneapolis, Paris and London are excluded from index trading due to liquidity constraints. Kansas is targeted by some indices but to a minor degree.

Besides the differences in speculative activity, we acknowledge that other factors affect the process governing volatilities. Specifically, the five exchanges trade different varietals of wheat, some of which even have slightly different growing and harvest cycles. Further, the composition of traders is not identical across commodity exchanges, which may affect how information is incorporated in prices, and hence volatilities. The most important drawback, however, is the heterogenous level of traded volumes across exchanges, which is likely to have an impact on average trading costs, and again on market efficiency. While our results need to be interpreted with this caveat in mind, our results strongly suggest that speculation aspects, rather than pure liquidity issues explain crosssectional differences in the behaviour of volatilities. ${ }^{23}$ A number of robustness tests, presented in Appendix section B, contribute to our interpretation.

Figure 1 presents monthly aggregates of open interest (OI) and trading volume (TV) for our sample. Contracts are in local currency but scaled such that they reflect equivalent quantities (i.e., the equivalent of 5000 bushels or 136 tons, which is the basis of the Chicago contracts). Chicago

\footnotetext{
${ }^{23}$ As speculation and liquidity are closely intertwined in many ways, we do not attempt to disentangle the two variables, which would be beyond the scope of this paper.
} 
Wheat is by far the most actively traded contract in our sample. Both OI and TV are approximately five times higher than for Kansas Wheat, the second-most actively traded contract. Trading activity in the Minneapolis Wheat contract and the two European contracts represents only a minor fraction (note the different scales of the axes; OI and TV differ substantially across contracts).

The figure also shows that trading activity has increased in all five markets over the sample period. The most pronounced increase can be observed from the mid-2000s onwards. The most highest absolute increase is observed in Chicago where open interest and trading volume have more than tripled. Part of the increase in trading volumes and OI is due to a large inflow of investment capital $^{24}$. In relative terms, Paris shows the most substantial increase in trading volume from virtually zero to a level comparable to Kansas in only one decade.

\subsection{Futures prices}

We use Thomson Reuters Datastream as our main source of commodities futures prices and related trading information ${ }^{25}$. Our sample covers the period from March 1995 to March 2015, with the exception of Paris Milling Wheat, for which data only exist from November 1998 onwards. The beginning of the sample period was set to the first date for which data on speculation activity is available.

We select the contract with the shortest time to delivery (i.e., the nearby contract), which is rolled into the next available maturity on the last Wednesday before the contract's expiration. For each contract we obtain on a daily frequency high and low prices and construct the weekly range from Wednesday to Tuesday by taking the lowest (highest) price of all daily low (high) prices during this weekly period. However, if a contract expires during the weekly period, we choose the daily high and low prices of the next maturity contract in order to avoid the inclusion of price gaps between

\footnotetext{
${ }^{24}$ For a broader discussion of this financialisation see Irwin and Sanders (2011) or Cheng and Xiong (2014) among others.

${ }^{25}$ Additionally, we use Bloomberg and FutureSource to confirm data validity and to fill in missing observations.
} 
Figure 1: Trading Activity 1995 to 2015

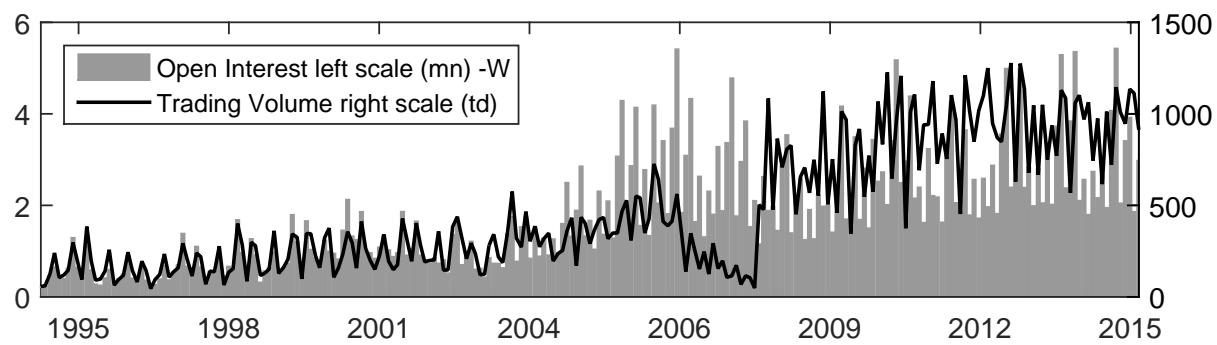

(a) Chicago Wheat (W), CBOT

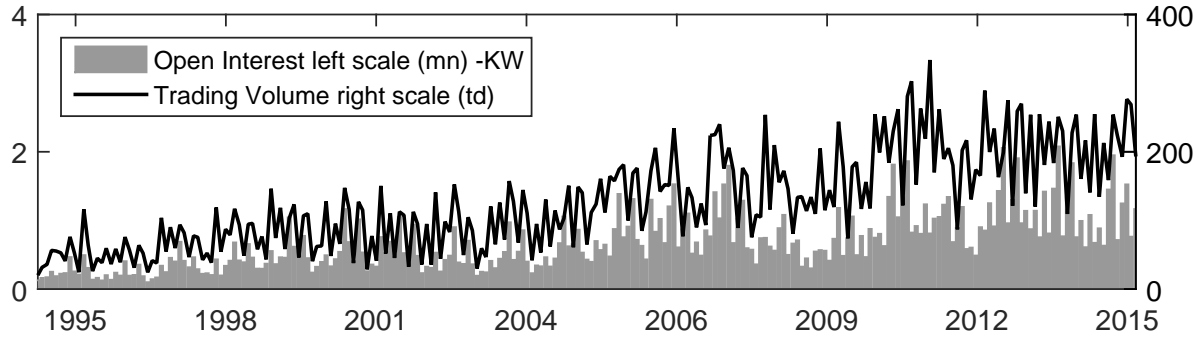

(b) Kansas Wheat (KW), KBOT

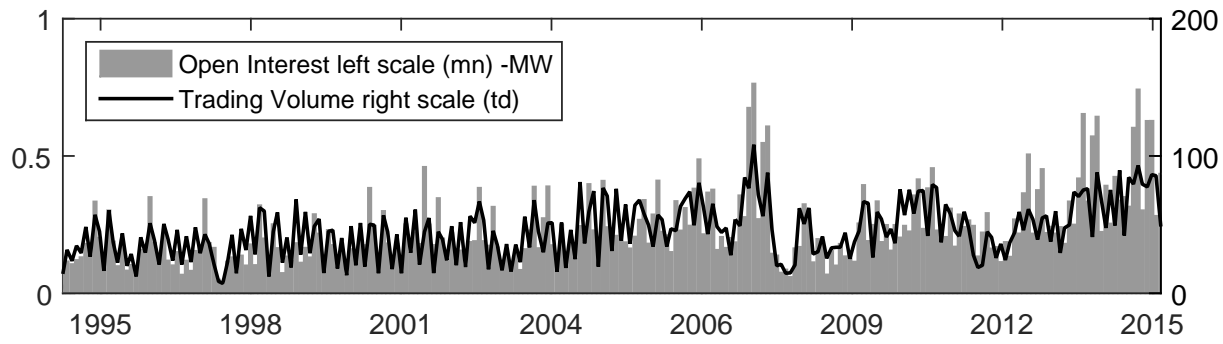

(c) Minneapolis Wheat (MW), MGEX

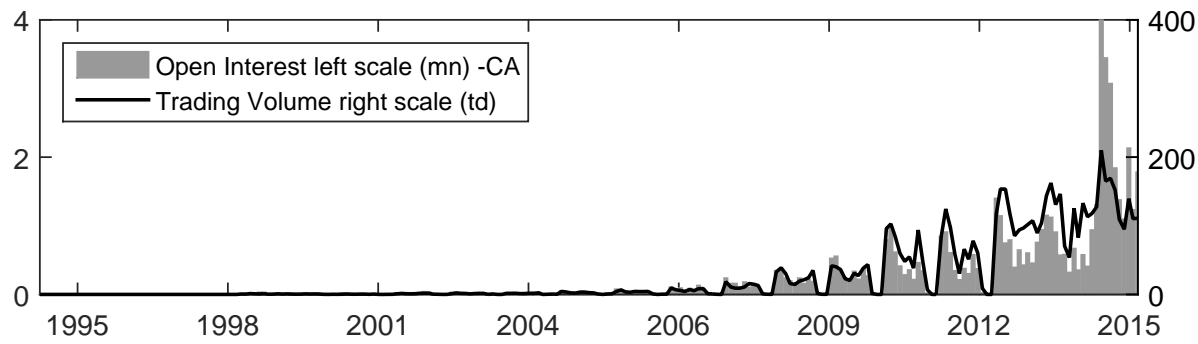

(d) Paris Milling Wheat (CA), LIFFE

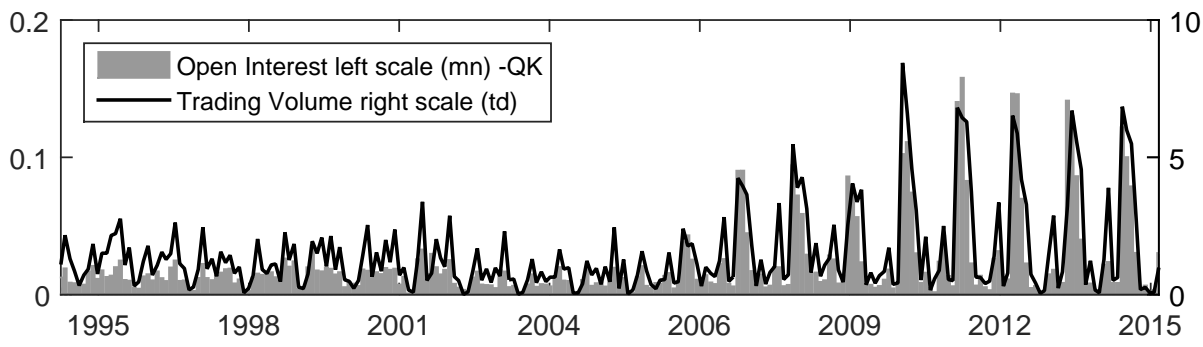

(e) London Feed Wheat (QK), ICE

The figure shows monthly aggregate open interest in million contracts (left axis) and trading volume in thousands of contracts (right axis). Contract sizes for $\mathrm{CA}$, and $\mathrm{QK}$ are adjusted to match the size of the contracts traded in the US. 
both contracts into the weekly price range. This mechanism ensures that (a) the selected futures prices mimic the unobservable spot price as closely as possible, (b) ranges match with speculation data and (c) ranges are not distorted by price gaps between different maturities. Weekly price range are calculated according to equation (1).

Table [1] reports the range-based volatility estimates according to equation (1) for the complete period (Panel A), the period from March 1995 to December 2005.12 (Panel B) and the period from January 2006 to March 2015 (Panel C). We split our data sample at the end of 2005 for two reasons: first, the CIT report has been introduced at this time, and second, structural breaks are identified around 2006 for all wheat contracts. ${ }^{26}$

Table 1: Distributional Characteristics of Wheat Nearby Futures The table presents the distributional characteristics of ranges of logarithmic prices $\left(\left[\ln \left(P_{t}^{\text {high }}\right)-\ln \left(P_{t}^{\text {low }}\right)\right]\right)$ of different wheat futures contracts with the shortest time to maturity. Wheat contracts are traded at the Chigoago Board of Trade (CBOT), Kansas City Board of Trade (KCBT), Minneapolis Grain Exchange (MGEX), Euronext Paris (LIFFE) and Intercontinental Exchange London. Coefficients $\rho_{1}$ and $\rho_{3}$ denote the autocorrelations at lag 1 and 3, respectively. All data are weekly observations.

\begin{tabular}{|c|c|c|c|c|c|c|c|c|c|}
\hline & Min & Median & Mean & Max & Std & Skew & Kurt & $\rho_{1}$ & $\rho_{3}$ \\
\hline \multicolumn{10}{|c|}{ Panel A: Ranges of Log Prices - Period: 1995.03-2015.03 } \\
\hline Chicago & 0.009 & 0.050 & 0.057 & 0.214 & 0.027 & 1.645 & 6.974 & $0.47^{* * *}$ & $0.40^{* * *}$ \\
\hline Kansas & 0.008 & 0.045 & 0.051 & 0.205 & 0.026 & 1.510 & 6.532 & $0.47^{* * *}$ & $0.40^{* * *}$ \\
\hline Minneapolis & 0.004 & 0.043 & 0.049 & 0.301 & 0.027 & 2.128 & 13.140 & $0.50^{* * *}$ & $0.40^{* * *}$ \\
\hline Paris ${ }^{\star}$ & 0.001 & 0.026 & 0.033 & 0.235 & 0.029 & 1.995 & 9.522 & $0.51^{* * *}$ & $0.47^{* * *}$ \\
\hline London & 0.002 & 0.027 & 0.033 & 0.174 & 0.023 & 2.093 & 9.525 & $0.38^{* * *}$ & $0.31^{* * *}$ \\
\hline \multicolumn{10}{|c|}{ Panel B: Ranges of Log Prices - Period: 1995.03-2006.01 } \\
\hline Chicago & 0.019 & 0.047 & 0.052 & 0.168 & 0.021 & 1.790 & 7.985 & $0.23^{* * *}$ & $0.21^{* * *}$ \\
\hline Kansas & 0.014 & 0.041 & 0.046 & 0.178 & 0.022 & 1.838 & 8.614 & $0.33^{* * *}$ & $0.24^{* * *}$ \\
\hline Minneapolis & 0.004 & 0.037 & 0.042 & 0.177 & 0.021 & 1.723 & 8.743 & $0.32^{* * *}$ & $0.28^{* * *}$ \\
\hline Paris ${ }^{\star}$ & 0.001 & 0.013 & 0.017 & 0.104 & 0.015 & 2.576 & 12.062 & $0.38^{* * *}$ & $0.17^{* * *}$ \\
\hline London & 0.003 & 0.023 & 0.027 & 0.174 & 0.018 & 3.058 & 18.810 & $0.16^{* * *}$ & $0.15^{* * *}$ \\
\hline \multicolumn{10}{|c|}{ Panel C: Ranges of Log Prices - Period: 2006.01-2015.03 } \\
\hline Chicago & 0.009 & 0.055 & 0.062 & 0.214 & 0.032 & 1.283 & 5.249 & $0.56^{* * *}$ & $0.47^{* * *}$ \\
\hline Kansas & 0.008 & 0.051 & 0.057 & 0.205 & 0.029 & 1.163 & 5.144 & $0.53^{* * *}$ & $0.47^{* * *}$ \\
\hline Minneapolis & 0.006 & 0.050 & 0.057 & 0.301 & 0.030 & 2.140 & 13.104 & $0.54^{* * *}$ & $0.39^{* * *}$ \\
\hline Paris & 0.004 & 0.040 & 0.046 & 0.235 & 0.030 & 1.935 & 9.195 & $0.33^{* * *}$ & $0.29^{* * *}$ \\
\hline London & 0.002 & 0.035 & 0.039 & 0.164 & 0.025 & 1.535 & 6.294 & $0.44^{* * *}$ & $0.32^{* * *}$ \\
\hline
\end{tabular}

* The time series for Paris runs from 1998.11 through 2015.03.

\footnotetext{
${ }^{26}$ We use the structural break test of Zeileis, Kleiber, Krämer, and Hornik (2003).
} 


\subsection{Excess speculation}

We use the standard measure of excess speculation, Working's T-index. Working (1960) argues that in a technical sense the index relates excess long or short speculation to the total amount of hedging. Following Sanders, Irwin, and Merrin (2010), the index is generated from data of the Commitments of Traders report (COT) provided by the US Commodity Futures Trading Commission (CFTC) ${ }^{27}$. The COT report classifies the positions held by market participants into those held by commercials and by non-commercials (plus a third group of "non-reported"). The report is available from March 1995 and lists the respective number of long and short contracts separately for each group ${ }^{28}$. Unfortunately, only the ICE provides a Commitment of Traders Report, similar to those provided by the CFTC, which however are available only since 2014 and therefore not sufficient for our analysis. ${ }^{29}$

We further use the Commodity Index Traders (CIT) supplement report, which contains more detailed information on the positions held by various agents in the market but is available only from January 2006. A substantial advantage of the CIT report is that it allows for a breakdown of positions held by swap dealers, who hedge index positions. The CIT report includes information about open positions of five trader categories: large non-commercials (speculators), large commercials (hedgers), large non-commercial spread investors, commodity index traders, and non-reportable traders (small speculative and hedging positions) ${ }^{30}$. Traditionally, the positions classified as commercials are considered as "hedgers", and the positions classified as non-commercials as "speculators".

\footnotetext{
${ }^{27}$ As noted by Haase, Zimmermann, and Zimmermann (2016), the T-index belongs to the category of direct speculative measures, which is preferrable from a methodological perspective.

${ }^{28}$ The COT report contains the allocation of open interest on each Tuesday for markets in which 20 or more traders hold positions equal to or above the reporting levels established by the CFTC. All data are released on Friday at 3:30 p.m. The published open interest for each market is aggregated across all contract maturities, and the aggregate of all long and short positions add up to the market's total open interest.

${ }^{29}$ The figures taken from this report indicate a low degree of speculative activity. For example, the position "other reportable" (speculation) accounts for less the $10 \%$ of both long and short positions in 2014 .

${ }^{30}$ The non-reporting traders in both reports cannot easily be classified as hedgers or speculators without strong assumptions. However, Sanders, Irwin, and Merrin (2010) point out that the speculation index is not particularly sensitive to the assignment of the non-reporting traders. For that reason, this group is omitted in our calculation of the T-index.
} 
Working's T-index is given by

$$
T_{C O T}=\left\{\begin{array}{cc}
1+\frac{S S}{H L+H S} & \text { if } H S \geq H L \\
1+\frac{S L}{H L+H S} & \text { if } H S<H L,
\end{array}\right.
$$

where the speculative positions are denoted by $S S$ for short speculation and $S L$ for long speculation, and the hedging positions are denoted by $H S$ for short hedging and $H L$ for long hedging, respectively. The innovations in Working's T-index are standardised and scaled by dividing the series by 100 , which yields more conveniently interpretable coefficient estimates. The $t$-values associated with the coefficients are unaffected by the procedure.

Figure 2: WT-Index 1995 to 2015

The figure shows Working's T-index based on the COT report over the period March 1995 to March 2015 and based on the CIT report over the period January 2006 to March 2015 (Chicago and Kansas only).
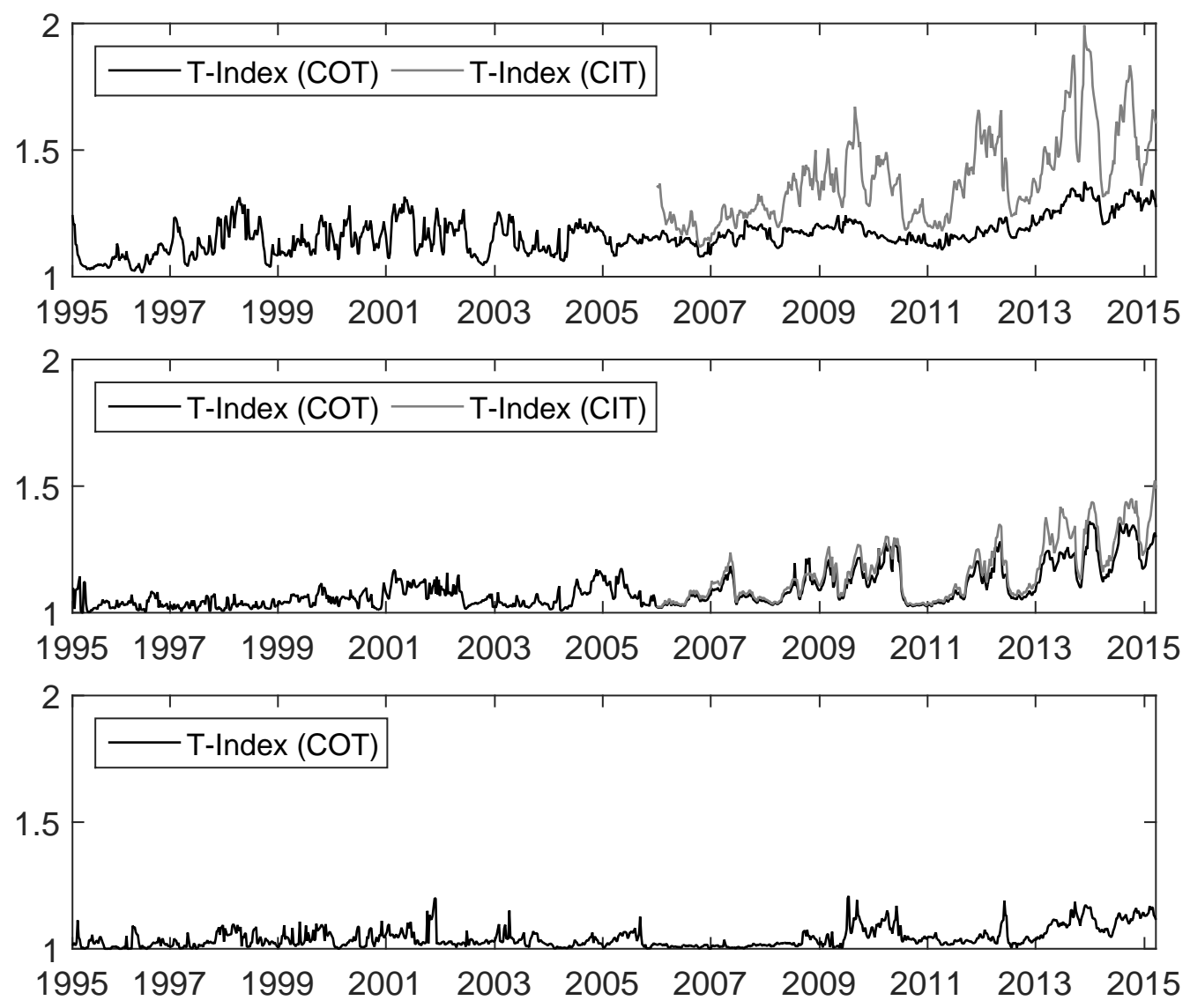
Figure 2 presents the evolution of excess speculation as measured by Working's T-index, based on the COT report over the period March 1995 to March 2015 and based on the CIT report over the period January 2006 to March 2015 (Chicago and Kansas only).

Visual inspection shows that Working's T-index varies substantially in terms of level and pattern across wheat contracts: while Chicago Wheat has been substantially exposed to financial speculation during the full observation period, Kansas Wheat has only been subject to a moderate level of speculation and only since around 2006. Excess speculation in Minneapolis Wheat has consistently been on a low level. The corresponding figures are presented in Table [2] Panel A, $\mathrm{B}^{31}$. The picture is even more pronounced if the Working-T index is calculated from the CIT report (Panel C; note at the CIT report is not available for Minneapolis since, according to the CFTC, no index speculators trade in this market). The respective innovations are reported in Table 7 in the appendix.

Table 2: Summary Statistics Excess Speculation

The table shows descriptive statistics for excess speculation in nearby wheat futures contracts traded at different US exchanges. Excess speculation is measured by the Working T-Index, based on information taken from the CFTC's COT and CIT reports.

\begin{tabular}{|c|c|c|c|c|c|c|c|c|c|c|}
\hline & Min & Median & Mean & Max & Std & Min & Median & Mean & Max & Std \\
\hline & \multicolumn{5}{|c|}{ Panel A: $1995.03-2015.03$ (COT) } & \multicolumn{5}{|c|}{ Panel B: 1995.03 - 2006.01 (COT) } \\
\hline Chicago & 1.02 & 1.16 & 1.17 & 1.38 & 0.07 & 1.02 & 1.13 & 1.14 & 1.32 & 0.07 \\
\hline Kansas & 1.00 & 1.06 & 1.09 & 1.36 & 0.08 & 1.00 & 1.04 & 1.06 & 1.17 & 0.04 \\
\hline \multirow[t]{2}{*}{ Minneapolis } & 1.00 & 1.03 & 1.04 & 1.21 & 0.04 & 1.00 & 1.03 & 1.03 & 1.20 & 0.03 \\
\hline & \multicolumn{5}{|c|}{ Panel C: 2006.01 - 2015.03 (COT) } & \multicolumn{5}{|c|}{ Panel D: 2006.01 - 2015.03 (CIT) } \\
\hline Chicago & 1.08 & 1.18 & 1.20 & 1.38 & 0.06 & 1.12 & 1.35 & 1.38 & 2.00 & 0.17 \\
\hline Kansas & 1.02 & 1.11 & 1.13 & 1.36 & 0.09 & 1.02 & 1.13 & 1.16 & 1.52 & 0.12 \\
\hline Minneapolis & 1.00 & 1.04 & 1.05 & 1.21 & 0.05 & n.a. & n.a. & n.a. & n.a. & n.a. \\
\hline
\end{tabular}

\section{Results and discussion}

In the following section we present the empirical results concerning the shock amplification parameter in our model, which measures the period-by-period shock transmission from the autoregressive

\footnotetext{
${ }^{31}$ Interestingly, the level of excess speculation in Chicago is comparable to the level reported by Working (1960) for the period 1954-1959. His values range between 1.081 and 1.41 at a five-year average of 1.22 . Unfortunately he does not provide values for Kansas and Minneapolis.
} 
(endogenous) model. Specifically, we test for herding and feedback-trading effects. Subsequently, we present results concerning the guilt parameter in our model, which measures the intra-period contribution of speculators to conditional volatility.

\subsection{Endogenous dynamics: shock amplification}

Estimates of the parameters of the endogenous model equation (2) are reported in Table 3 . Herding and feedback trading effects are measured by the shock amplification parameter $\alpha$. If the process governing conditional volatilities is comparable across wheat markets, cross-market differences in $\alpha$ should reflect speculation-induced effects. The shock amplification parameter should be higher in markets where speculators amplify next-period volatility through herding or feedback trading, and it should be lower in markets where shocks are more efficiently absorbed. An absence of cross-market differences would indicate that speculative activity has no impact at all.

Our estimation results clearly show that, although an almost homogeneous good is traded, shock amplification varies substantially between wheat markets, which supports the view that speculation does indeed have an impact on conditional volatility. Furthermore, the results show that shock amplification varies over time but to different extents. These findings remain robust after controlling for wheat market specific effects like seasonal and time to maturity effects as well as for inventories levels. ${ }^{32}$

Estimation results for the full period are presented in Table 4, Panel A (for Chicago, Kansas, Minneapolis and London) and Panel B (also including Paris where data are only available from November 1998 onwards). Chicago, the market with the highest exposure to speculation, is characterised by the lowest shock amplification parameter $(\alpha=.17)$. The estimate for London, on the other hand-the market with the lowest exposure to speculation-is approximately $40 \%$ higher $(\alpha=$

\footnotetext{
${ }^{32}$ See Appendix section B Robustness.
} 
.23). This result clearly contradicts the hypothesis by authors such as De Long, Shleifer, Summers, and Waldmann (1990), Shiller, Fischer, and Friedman (1984) and Shleifer and Summers (1990) that herding behaviour and feedback trading by speculative traders would amplify shocks. Rather, our finding is consistent with the traditional view that speculation contributes to market efficiency.

By splitting the sample in halves (Table 4, Panels C and D), we account for the substantial increase of speculative capital in more recent times. Although index-induced speculation massively gained importance from 2006 onwards, the shock amplification parameter for Chicago remained almost unchanged. The shock amplification parameter for Kansas decreased by $20 \%$ and became closer to the Chicago value. The opposite can be observed for wheat markets which are not part of index allocation: in Minneapolis and London, the shock amplification parameter increased by approximately $30 \%$ and $60 \%$, respectively.

These results corroborate our previous finding: again, a lower degree of shock amplification is observed in those wheat markets where the majority of speculation takes place. A particularly noteworthy finding pertains to Kansas. Although Kansas became part of index speculation in the second period, the shock amplification parameter decreased from the first to the second period. This is in stark contrast to all markets without index speculation, where the shock amplification parameter increased from the first to the second period. Lower shock amplification in markets with larger speculative activity is consistent with the classical view that speculation dampens volatility, predominantly by making markets more efficient or by providing liquidity on that side of the market where liquidity is most desired.

At the same time, our results suggest that cross-sectional differences in $\alpha$ cannot be explained by trading volumes (as a proxy for liquidity) or transaction costs alone. The most significant shift in volumes has occurred in Paris (by a factor of 29), and to a lesser extent in London (by a factor of 2.6, approximately the same factor as in Chicago), or Minneapolis (1.6). The observed increase 
in $\alpha$ for these markets is clearly inconsistent with liquidity being the dominant driving force behind the shock amplification parameter.

Table 3: Volatility Dynamics Base Model

The table reports maximum likelihood estimates of a CARR(1,1) model of weekly log-ranges for a cross section of nearby wheat futures.

\begin{tabular}{|c|c|c|c|c|c|}
\hline & Chicago & Kansas & Minneapolis & Paris & London \\
\hline \multicolumn{6}{|c|}{ Panel A: 1995.03 - 2015.03 } \\
\hline \multirow[t]{2}{*}{$\omega$} & $0.0014^{* * *}$ & $0.0017^{* * *}$ & $0.0017^{* * *}$ & & $0.0026^{* * *}$ \\
\hline & $(2.5956)$ & $(2.8923)$ & $(2.9890)$ & & $(3.5130)$ \\
\hline \multirow[t]{2}{*}{$\alpha$} & $0.1666^{* * *}$ & $0.2011^{* * *}$ & $0.1872^{* * *}$ & & $0.2268^{* * *}$ \\
\hline & $(7.8442)$ & $(8.4236)$ & $(8.1708)$ & & $(7.1194)$ \\
\hline \multirow[t]{2}{*}{$\beta$} & $0.8089^{* * *}$ & $0.7661^{* * *}$ & $0.7800^{* * *}$ & & $0.6976^{* * *}$ \\
\hline & $(30.9461)$ & $(25.5934)$ & $(27.3545)$ & & $(15.0988)$ \\
\hline \multirow[t]{2}{*}{$\sigma$} & $0.3640^{* * *}$ & $0.4026^{* * *}$ & $0.4330^{* * *}$ & & $0.5827^{* * *}$ \\
\hline & $(45.6753)$ & $(45.6752)$ & $(45.6789)$ & & $(45.6835)$ \\
\hline llik & -2674.8394 & -2696.9042 & -2677.1403 & & -2872.6423 \\
\hline \multicolumn{6}{|c|}{ Panel B: 1998.11 - 2015.03} \\
\hline \multirow[t]{2}{*}{$\omega$} & $0.0007^{*}$ & $0.0010^{* *}$ & $0.0011^{* *}$ & 0.0001 & $0.0021^{* * *}$ \\
\hline & $(1.7184)$ & $(1.9948)$ & $(2.2146)$ & $(0.4688)$ & $(3.0302)$ \\
\hline \multirow[t]{2}{*}{$\alpha$} & $0.1407^{* * *}$ & $0.1783^{* * *}$ & $0.1644^{* * *}$ & $0.1638^{* * *}$ & $0.2226^{* * *}$ \\
\hline & $(6.6146)$ & $(7.1416)$ & $(6.9138)$ & $(7.5448)$ & $(6.5642)$ \\
\hline \multirow[t]{2}{*}{$\beta$} & $0.8467^{* * *}$ & $0.8034^{* * *}$ & $0.8154^{* * *}$ & $0.8411^{* * *}$ & $0.7179^{* * *}$ \\
\hline & $(34.4983)$ & $(27.2098)$ & $(28.9550)$ & $(39.6828)$ & $(15.5081)$ \\
\hline \multirow[t]{2}{*}{$\sigma$} & $0.3686^{* * *}$ & $0.4023^{* * *}$ & $0.4414^{* * *}$ & $0.6268^{* * *}$ & $0.5944^{* * *}$ \\
\hline & $(41.3105)$ & $(41.3084)$ & $(41.3131)$ & $(41.3288)$ & $(41.3140)$ \\
\hline llik & -2165.4653 & -2199.5169 & -2170.3645 & -2401.2540 & -2312.3148 \\
\hline \multicolumn{6}{|c|}{ Panel C: $1995.03 / 1998.11$ - 2006.01} \\
\hline \multirow[t]{2}{*}{$\omega$} & $0.0060^{* * *}$ & $0.0062^{* * *}$ & $0.0024^{* *}$ & $0.0005^{*}$ & $0.0045^{* * *}$ \\
\hline & (3.1818) & $(3.3117)$ & $(2.5042)$ & $(1.7433)$ & $(2.8310)$ \\
\hline \multirow[t]{2}{*}{$\alpha$} & $0.1570^{* * *}$ & $0.2163^{* * *}$ & $0.1670^{* * *}$ & $0.1483^{* * *}$ & $0.1779^{* * *}$ \\
\hline & $(5.6252)$ & $(6.1694)$ & $(5.6542)$ & $(4.4359)$ & $(4.3225)$ \\
\hline \multirow[t]{2}{*}{$\beta$} & $0.7271^{* * *}$ & $0.6483^{* * *}$ & $0.7772^{* * *}$ & $0.8213^{* * *}$ & $0.6545^{* * *}$ \\
\hline & $(14.0060)$ & $(10.2660)$ & $(18.3863)$ & $(20.1189)$ & $(7.6934)$ \\
\hline \multirow[t]{2}{*}{$\sigma$} & $0.3331^{* * *}$ & $0.3876^{* * *}$ & $0.4476^{* * *}$ & $0.7133^{* * *}$ & $0.5786^{* * *}$ \\
\hline & $(33.5596)$ & $(33.5608)$ & $(33.5628)$ & $(27.3542)$ & $(33.5668)$ \\
\hline llik & -1520.8351 & -1518.5671 & -1507.1616 & -1244.3204 & -1648.6028 \\
\hline \multicolumn{6}{|c|}{ Panel D: 2006.01 - 2015.03 } \\
\hline \multirow[t]{2}{*}{$\omega$} & 0.0005 & 0.0004 & $0.0023^{* *}$ & $0.0011^{*}$ & $0.0030^{* *}$ \\
\hline & $(0.9660)$ & $(0.8514)$ & $(2.1075)$ & $(1.7102)$ & $(2.2703)$ \\
\hline \multirow[t]{2}{*}{$\alpha$} & $0.1567^{* * *}$ & $0.1731^{* * *}$ & $0.2140^{* * *}$ & $0.1841^{* * *}$ & $0.2799^{* * *}$ \\
\hline & $(5.2393)$ & $(5.6403)$ & $(5.6071)$ & $(5.6381)$ & $(5.7488)$ \\
\hline \multirow[t]{2}{*}{$\beta$} & $0.8361^{* * *}$ & $0.8205^{* * *}$ & $0.7466^{* * *}$ & $0.7970^{* * *}$ & $0.6514^{* * *}$ \\
\hline & $(25.7370)$ & $(24.8375)$ & $(15.3887)$ & $(20.9794)$ & $(9.5839)$ \\
\hline \multirow[t]{2}{*}{$\sigma$} & $0.3916^{* * *}$ & $0.4114^{* * *}$ & $0.4120^{* * *}$ & $0.5430^{* * *}$ & $0.5796^{* * *}$ \\
\hline & $(30.9884)$ & $(30.9913)$ & $(30.9869)$ & $(30.9972)$ & $(30.9961)$ \\
\hline llik & -1168.9361 & -1188.8930 & -1175.2761 & -1178.6257 & -1230.8419 \\
\hline
\end{tabular}




\subsection{Impact of speculation on conditional volatility: guilty or innocent}

We now turn to the guilt parameter in our model. The parameter $\gamma$ captures the intra-period effects of excess speculative trading, proxied by the innovations in Working's T-index. A positive innovation indicates an increase in speculative positions. According to Working, such an increase would technically not be necessary to match hedging needs and can therefore be treated as an indicator of "unnecessary" trading activities among speculators (in particular, noise trading and intra-period herding).

In analogy to the standards of evidence in legal proceedings, a positive and significant estimate of $\gamma$ would be sufficient evidence that excess speculative trading indeed increases conditional volatility and should therefore justify pronouncing speculators as "guilty" of this charge. A positive but insignificant estimate of $\gamma$ might point in the same direction but should, under a presumption of innocence, not be sufficient to prove guilt without a reasonable doubt and therefore lead a to a verdict of "not guilty" or "not proven". A negative sign, on the other hand, would indicate the opposite and should therefore lead to full acquittal and a pronunciation as "innocent". 33

Since the estimation of the guilt parameter $\gamma$ requires data on excess speculation, which is only available for US markets, our results will be limited to Chicago, Kansas and Minneapolis. We present two specifications. First, we use innovations in Working's T-index calculated from the information in the COT report, which is available for the complete observation period. Then, we use innovations in Working's T-index calculated from the information in the CIT report. The CIT information is more detailed (see above) but is only available for a shorter observation period and only for Chicago and Kansas.

\footnotetext{
${ }^{33}$ Of course, speculative intensity might be influenced by other (omitted) variables like an unexpected changes in aggregated risk aversion. However, we argue that the Woring's T-index is in line with the regulatory measures of speculation intensity, i.e. the CFTC trader position data, independent of its driving factors.
} 
Table 4: Volatility Dynamics dWT (COT)

The table reports maximum likelihood estimates of a CARRX $(1,1)$ model (equation 2) of weekly log-ranges for a cross section of nearby wheat futures. The exogenous variable are weekly innovations of the Working T-Index, calculated from the information contained in the COT report of the CFTC.

\begin{tabular}{|c|c|c|c|}
\hline & Chicago & Kansas & Minneapolis \\
\hline \multicolumn{4}{|c|}{ Panel A: 1995.03 - 2015.03 } \\
\hline \multirow[t]{2}{*}{$\omega$} & $0.0013^{* * *}$ & $0.0018^{* * *}$ & $0.0017^{* * *}$ \\
\hline & (2.5798) & $(3.1485)$ & $(3.0345)$ \\
\hline \multirow[t]{2}{*}{$\alpha$} & $0.1517^{* * *}$ & $0.1965^{* * *}$ & $0.1874^{* * *}$ \\
\hline & $(7.1641)$ & $(8.4132)$ & $(8.1934)$ \\
\hline \multirow[t]{2}{*}{$\beta$} & $0.8258^{* * *}$ & $0.7678^{* * *}$ & $0.7789^{* * *}$ \\
\hline & $(31.9670)$ & $(26.1905)$ & $(27.2144)$ \\
\hline \multirow[t]{2}{*}{$\sigma$} & $0.3623^{* * *}$ & $0.4003^{* * *}$ & $0.4325^{* * *}$ \\
\hline & $(45.6778)$ & $(45.6754)$ & $(45.6758)$ \\
\hline \multirow[t]{2}{*}{$\gamma$} & $-0.1256^{* * *}$ & $-0.1260^{* * *}$ & -0.0775 \\
\hline & $(-3.2353)$ & $(-3.3849)$ & $(-1.5965)$ \\
\hline llik & -2679.8869 & -2702.6213 & -2678.3882 \\
\hline \multicolumn{4}{|c|}{ Panel B: 1995.03 - 2006.01 } \\
\hline \multirow[t]{2}{*}{$\omega$} & $0.0057^{* * *}$ & $0.0060^{* * *}$ & $0.0024^{* *}$ \\
\hline & (3.1597) & $(3.2685)$ & $(2.5140)$ \\
\hline \multirow[t]{2}{*}{$\alpha$} & $0.1467^{* * *}$ & $0.2094^{* * *}$ & $0.1695^{* * *}$ \\
\hline & $(5.2878)$ & $(5.9750)$ & (5.7124) \\
\hline \multirow[t]{2}{*}{$\beta$} & $0.7433^{* * *}$ & $0.6608^{* * *}$ & $0.7729^{* * *}$ \\
\hline & $(14.5421)$ & $(10.5639)$ & $(17.9914)$ \\
\hline \multirow[t]{2}{*}{$\sigma$} & $0.3316^{* * *}$ & $0.3870^{* * *}$ & $0.4472^{* * *}$ \\
\hline & (33.5564) & $(33.5600)$ & (33.5627) \\
\hline \multirow[t]{2}{*}{$\gamma$} & $-0.1222^{* *}$ & -0.0960 & -0.0669 \\
\hline & $(-2.3062)$ & $(-1.3871)$ & $(-0.9786)$ \\
\hline llik & -1523.4401 & -1519.5131 & -1507.6335 \\
\hline \multicolumn{4}{|c|}{ Panel C: 2006.01 - 2015.03 } \\
\hline \multirow[t]{2}{*}{$\omega$} & 0.0004 & 0.0006 & $0.0024^{* *}$ \\
\hline & (1.0713) & (1.2188) & $(2.2448)$ \\
\hline \multirow[t]{2}{*}{$\alpha$} & $0.1213^{* * *}$ & $0.1742^{* * *}$ & $0.2033^{* * *}$ \\
\hline & $(4.1330)$ & $(5.5129)$ & $(5.4520)$ \\
\hline \multirow[t]{2}{*}{$\beta$} & $0.8721^{* * *}$ & $0.8154^{* * *}$ & $0.7563^{* * *}$ \\
\hline & $(27.7351)$ & $(23.5564)$ & (16.0969) \\
\hline \multirow[t]{2}{*}{$\sigma$} & $0.3875^{* * *}$ & $0.4086^{* * *}$ & $0.4110^{* * *}$ \\
\hline & $(30.9943)$ & $(30.9911)$ & $(30.9914)$ \\
\hline \multirow[t]{2}{*}{$\gamma$} & $-0.1962^{* * *}$ & $-0.1050^{* *}$ & -0.1127 \\
\hline & $(-3.3290)$ & $(-2.5012)$ & $(-1.5713)$ \\
\hline llik & -1173.9681 & -1192.2333 & -1176.4486 \\
\hline
\end{tabular}

COT Report Estimated for the complete period, all guilt parameters are consistently negative but significant only for Chicago and Kansas, indicating that an increase in excess speculation dampens contemporaneous volatility (Table 4, Panel A) ${ }^{34}$. From a purely statistical point of view, our results therefore suggest that speculators should be pronounced innocent of the charge of increasing

\footnotetext{
${ }^{34}$ Compared to our baseline results (see above), the estimates of the shock amplification parameters remain largely unaffected by the inclusion of the exogenous variable and will therefore be not discussed again.
} 
contemporaneous volatility by their trading activities.

Given the relevance of food price volatility for the real economy, a second question is of equal importance: what is the economic benefit of the presence of speculators in these markets? We therefore express the guilt parameter in economic terms ${ }^{35}$ : the average impact of a $10 \%$ increase in Working's T-Index is a $9.2 \%$ decrease in intra-period volatility in Chicago and an $11.2 \%$ decrease in intra-period volatility in Kansas. This result highlights the importance of speculators' activities in U.S. wheat markets. In stark contrast to the assumption underlying recent regulatory changes, our results indicate that speculators make a substantial positive contribution to the smoothing of the price discovery process.

In a next step, we analyse the effect of more pronounced index investment in more recent times by comparing the first half of the observation period with the second half of the observation period (where index investment gained importance). The results are presented in Table 4 (Panels B and C). The volatility-dampening effect of speculative activity has increased since 2006, especially in Chicago and Kansas where index speculation takes place. Expressed in economic terms, the average effect of a $10 \%$ increase in Working's T-Index in Chicago increases from an $8 \%$ decrease in intraperiod valatility before 2006 to a $20 \%$ decrease after 2006. In Kansas, the volatility-dampening effect of excess speculation is only significant in the after-2006 period (9.5\%). In Minneapolis, where no index speculation takes place, the dampening effect is not significant in either of the two periods. These results again contradict the view that excess speculation is responsible for increases in price volatility. Empirically, it even appears that speculators have protected markets from larger price spikes.

CIT Report Many authors, including Ederington and Lee (2002), Stoll and Whaley (2010), Sanders, Irwin, and Merrin (2010) and Irwin and Sanders (2011), would argue that these findings

\footnotetext{
${ }^{35}$ Note that the gamma coefficients are scaled by their standard deviations.
} 
might be diluted because the COT report underestimates the true number of speculative swap dealers (so-called "index swap dealers"). In the present analysis, this statement is supported at least for Chicago (see Figure 2, above) where the degree of excess speculation considerably changed when we based the calculation of Working's T-index on the CIT report instead of the COT report.

Furthermore, index-linked investments assume a special role in this context: commodity investment schemes usually follow mechanical rules in their asset allocation, rather than continuous trading based on information newly arriving in the market. It could therefore be argued that these investments belong to the "unskilled" category. The fact that the major commodity indices place their trades almost simultaneously when expiring contracts are rolled over can additionally contribute to increasing volatility, see Henderson, Pearson, and Wang (2015). On the other hand, the liquidity service provided by long-only products may be particularly valuable to hedgers, who are usually on the short side.

We examine the robustness of our results to such measurement issues by re-estimating our model, but with Working's T-index calculated from the information in the CIT report instead of the COT report. In the CIT report, index swap dealers are classified as speculators and not as hedgers as in the COT report. The CIT report is available only for Chicago and Kansas (i.e., the commodity markets where index investment takes place) and only from January 2006 onwards.

Table [5] presents the estimation results for the complete period January 2006 to March 2015 and for two sub-periods ${ }^{36}$. Using the CIT instead of the COT classification does not change the results for the complete period: the estimates of the guilt parameters are consistently negative, again indicating that speculators are innocent of the charge of increasing volatility.

The results reported up until now indicate that speculation has a generally dampening effect on volatility. As yet, it is an open question whether it can also counteract excess volatility in particular

\footnotetext{
${ }^{36}$ We do not comment the alpha and beta coefficients since they are similar to the previous estimates.
} 
Table 5: Volatility Dynamics dWT (SCOT)

The table reports maximum likelihood estimates of a CARRX $(1,1)$ model (equation 2) of weekly log-ranges for a cross section of nearby wheat futures. The exogenous variable are weekly innovations of the Working T-Index, calculated from the information contained in the CIT report of the CFTC.

\begin{tabular}{|c|c|c|c|c|c|c|}
\hline & \multicolumn{2}{|c|}{$2006.01-2015.03$} & \multicolumn{2}{|c|}{$2006.01-2009.12$} & \multicolumn{2}{|c|}{$2010.01-2015.03$} \\
\hline & Chicago & Kansas & Chicago & Kansas & Chicago & Kansas \\
\hline \multirow[t]{2}{*}{$\omega$} & 0.0005 & 0.0006 & $0.0104^{* *}$ & $0.0129^{* *}$ & 0.0005 & 0.0007 \\
\hline & $(1.1922)$ & $(1.1411)$ & $(2.1609)$ & $(2.1661)$ & $(1.1242)$ & $(1.0799)$ \\
\hline \multirow[t]{2}{*}{$\alpha$} & $0.1307^{* * *}$ & $0.1728^{* * *}$ & $0.2906^{* * *}$ & $0.2763^{* * *}$ & $0.0882^{* * *}$ & $0.1606^{* *}$ \\
\hline & $(4.2452)$ & $(5.4164)$ & $(4.4085)$ & $(3.9652)$ & $(2.8295)$ & $(4.3644)$ \\
\hline \multirow[t]{2}{*}{$\beta$} & $0.8609^{* * *}$ & $0.8175^{* * *}$ & $0.5752^{* * *}$ & $0.5399^{* * *}$ & $0.9012^{* * *}$ & $0.8244^{* *}$ \\
\hline & $(25.5522)$ & $(23.4118)$ & $(5.3105)$ & $(4.0455)$ & $(26.1672)$ & $(20.0556)$ \\
\hline \multirow[t]{2}{*}{$\sigma$} & $0.3849^{* * *}$ & $0.4085^{* * *}$ & $0.3316^{* * *}$ & $0.3520^{* * *}$ & $0.4127^{* * *}$ & $0.4384^{* *}$ \\
\hline & (30.9930) & (30.9911) & $(20.4002)$ & (20.4008) & (23.3399) & (23.3351) \\
\hline \multirow[t]{2}{*}{$\gamma$} & $-0.1465^{* * *}$ & $-0.0910^{* *}$ & $-0.3681^{* * *}$ & $-0.4418^{* * *}$ & $-0.1592^{* * *}$ & $-0.0842^{*}$ \\
\hline & $(-4.2135)$ & $(-2.5178)$ & $(-2.9022)$ & $(-2.9981)$ & $(-3.7950)$ & $(-1.9128)$ \\
\hline llik & -1177.2196 & -1192.3273 & -483.5001 & -492.2310 & -705.5287 & -711.9479 \\
\hline
\end{tabular}

distress periods. This is intuitive, due to the additional liquidity provided by speculators, as long as the majority of speculators take the opposite position as commercials (which is typically the case). In order to examine this hypothesis, we split the period January 2006 to March 2015 into two subperiods - a distress period (2006 to 2009) that was characterised by unusually high volatilities (see above) and a post-crisis period (2010 to 2015) in which volatilities receded again - and re-estimate our model within the sub-periods.

In both sub-periods, the estimates of all guilt parameters are consistently negative and statistically significant, again indicating that speculators are innocent of the charge of increasing volatility. Remarkable is the fact that the dampening effect in the distress period is much stronger than in the post-crisis period: in economic terms, a 10\% increase in Working's T-Index in the distress period reduces intra-period volatility by $14.9 \%$ in Chicago and $33.2 \%$ in Kansas, compared to $6.8 \%$ and $6.5 \%$ in post-crises period, respectively. Hence, our findings do not only provide empirical evidence that speculators are innocent of the charge of increasing volatility. On the contrary, they show that (index) speculators make a positive contribution by reducing intra-period volatility in wheat markets, especially during times of distress. 


\section{Exogenous threshold model: volatility regimes}

Finally, we address Working's argument that a certain amount of excess speculation is a necessary condition for a well-functioning market. Assuming that a well-functioning market is also associated with low volatility and moderate short-term shock transmission, there is no empirical evidence for Working's argument so far. In this section, we analyse the impact of different levels of excess speculation on conditional volatility by using an exogenous threshold CARR model (TCARR; developed by Chen, Gerlach, and Lin (2008)). The TCARR model captures the asymmetry of conditional volatility. According to Chen et al. (2008) it is more accurate than the symmetric CARR model. We apply the Working- $T$ index to determine the exogenous regime change. In our context, the TCARRX model for two regimes can be written as:

$$
\begin{gathered}
R_{t}=\lambda_{t} \varepsilon_{t}, \\
\lambda_{t}= \begin{cases}\omega^{(1)}+\sum_{i=1}^{p} \alpha_{i}^{(1)} R_{t-i}+\sum_{j=1}^{q} \beta_{j}^{(1)} \lambda_{t-j}+\sum_{k=1}^{L} \gamma_{k}^{(1)} X_{k} & \text { if } W T_{t-1} \leq t h, \\
\omega^{(2)}+\sum_{i=1}^{p} \alpha_{i}^{(2)} R_{t-i}+\sum_{j=1}^{q} \beta_{j}^{(2)} \lambda_{t-j}+\sum_{k=1}^{L} \gamma_{k}^{(2)} X_{k} & \text { if } W T_{t-1}<t h,\end{cases}
\end{gathered}
$$

where the threshold value th is constrained to lie within the range of the exogenous threshold variable $W T_{t-1}$. Table 6 provides the TCARRX model estimation results over the full sample period, where the exogenous threshold variable $W T_{t-1}$ is based on the COT report.

Our results support Working's hypothesis that sufficient excess speculation is a necessary condition for a well functioning market. Across all markets, we find that regimes with low excess speculation show on average: (a) 10\% higher volatility, (b) almost $50 \%$ higher shock amplification and (c) substantially larger guilt parameters. If, on the other hand, the level of excess speculation is sufficiently high, the anatomy of volatility converges in all markets to the pattern of low volatility 
and moderate short-term shock transmission preferred by regulators and public perception.

Table 6: Threshold Model

\begin{tabular}{|c|c|c|c|c|c|c|}
\hline & \multicolumn{2}{|c|}{ Chicago } & \multicolumn{2}{|c|}{ Kansas } & \multicolumn{2}{|c|}{ Minneapolis } \\
\hline & $<t h$ & $>=t h$ & $<t h$ & $>=t h$ & $<t h$ & $>=t h$ \\
\hline$\omega$ & $\begin{array}{r}0.0045 \\
(1.5598)\end{array}$ & $\begin{array}{r}0.0006 \\
(1.7489)\end{array}$ & $\begin{array}{r}0.0056 \\
(3.1544)\end{array}$ & $\begin{array}{r}0.0007 \\
(1.6534)\end{array}$ & $\begin{array}{r}0.0000 \\
(0.0001)\end{array}$ & $\begin{array}{r}0.0023 \\
(3.2470)\end{array}$ \\
\hline$\alpha$ & $\begin{array}{r}0.2232 \\
(3.9287)\end{array}$ & $\begin{array}{r}0.1218 \\
(6.3062)\end{array}$ & $\begin{array}{r}0.2718 \\
(6.6428)\end{array}$ & $\begin{array}{r}0.1370 \\
(5.3200)\end{array}$ & $\begin{array}{r}0.2488 \\
(4.7909)\end{array}$ & $\begin{array}{r}0.1629 \\
(6.9342)\end{array}$ \\
\hline$\beta$ & $\begin{array}{r}0.6553 \\
(7.5941)\end{array}$ & $\begin{array}{r}0.8673 \\
(39.5529)\end{array}$ & $\begin{array}{r}0.6166 \\
(10.3420)\end{array}$ & $\begin{array}{r}0.8500 \\
(30.2452)\end{array}$ & $\begin{array}{r}0.7499 \\
(10.6647)\end{array}$ & $\begin{array}{r}0.7835 \\
(25.5193)\end{array}$ \\
\hline$\gamma$ & $\begin{array}{r}-0.5530 \\
(-3.7883)\end{array}$ & $\begin{array}{r}-0.0989 \\
(-2.5364)\end{array}$ & $\begin{array}{r}-0.1945 \\
(-1.9226)\end{array}$ & $\begin{array}{r}-0.1010 \\
(-2.8558)\end{array}$ & $\begin{array}{r}-0.2878 \\
(-1.7249)\end{array}$ & $\begin{array}{r}-0.0163 \\
(-0.3191)\end{array}$ \\
\hline$\sigma$ & \multicolumn{2}{|c|}{$\begin{array}{c}0.3582 \\
(45.6780)\end{array}$} & \multicolumn{2}{|c|}{$\begin{array}{c}0.3968 \\
(45.6776)\end{array}$} & \multicolumn{2}{|c|}{$\begin{array}{c}0.4303 \\
(45.6616)\end{array}$} \\
\hline th & \multirow{2}{*}{\multicolumn{2}{|c|}{1.0908}} & \multicolumn{2}{|c|}{1.0486} & \multicolumn{2}{|c|}{1.0174} \\
\hline $\mathrm{p}(\mathrm{obs})>$ th & & & \multirow{2}{*}{\multicolumn{2}{|c|}{-2711.6811}} & & \\
\hline llik & \multicolumn{2}{|c|}{-2691.8150} & & & \multicolumn{2}{|c|}{-2683.7927} \\
\hline mean range & 0.0601 & 0.0559 & 0.0545 & 0.0489 & 0.0530 & 0.0473 \\
\hline std range & 0.0296 & 0.0266 & 0.0282 & 0.0246 & 0.0305 & 0.0252 \\
\hline
\end{tabular}

\section{Conclusion}

The world food price crisis of 2007 and 2008 was an impressive demonstration of the adverse effects of food price volatility on food security, with far-reaching implications for the political and economic stability of developing countries. A search for the guilty party ensued and soon enough a group of likely-looking suspects was found: speculators. After all, capital inflow to commodity markets had increased over the same period in which food price volatility had reached unusually high levels.

Possibly due to the enormous public pressure, regulators failed to search for more stringent causal evidence and simply went ahead, prematurely pronouncing speculators as the guilty party. Stricter position limits were imposed on speculators, especially in agricultural markets (see the MiFIDII Directive in the EU and the Dodd-Frank Act in the US). Such regulatory decisions could be regarded as wise if speculation did in fact increase food price volatility. They could still be regarded as acceptable (although somewhat discriminatory in the context of an open and fair marketplace) 
if speculation had no general impact on price volatility. However, they would have to be regarded as extremely unwise if the activities of speculators actually reduced food price volatility.

Our paper contributes to the discussion of whether speculation impact food price volatility by focusing on a cross-section that exclusively consists of wheat futures contracts, traded at five different commodity exchanges (Chicago, Kansas, Minneapolis, London and Paris). Each commodity exchange represents price discovery of wheat futures contracts with immediate and local delivery, whereas exposure to speculative activity varies considerably between the commodity exchanges.

Based on our results, we find no evidence to support the regulators' premature judgment, and thus conclude that speculators should be fully acquitted. Indeed, we found the opposite of what the regulatory initiatives implicitly assume: excess speculation dampens volatility and reduces shock amplification, particularly in times of distress (notably, the world food price crisis of 2007 and 2008). Our findings are fully consistent with Working's hypothesis that, by providing liquidity and/or increasing informational efficiency, a certain amount of excess speculation may be essential for a well-functioning market.

The bitter irony is that the imposition of position limits by regulations such as MiFID-II and the Dodd-Frank Act is not only costly and superfluous but counter-productive and self-defeating. If strict position limits are implemented, they are likely to exacerbate price volatility, and this particularly in periods of distress when volatility is already painfully high. Hence, we urge regulators to re-evaluate the causes of high food price volatility and carefully choose instruments that can actually reduce price volatility. 


\section{References}

Alizadeh, S., M. W. Brandt, and F. X. Diebold (2002): "Range-based estimation of stochastic volatility models," The Journal of Finance, 57(3), 1047-1091.

Andersen, T. G., And T. Bollerslev (1998): "Answering the skeptics: Yes, standard volatility models do provide accurate forecasts," International economic review, pp. 885-905.

Aulerich, N. M., S. H. Irwin, and P. Garcia (2013): "Bubbles, food prices, and speculation: evidence from the CFTC's daily large trader data files," National Bureau of Economic Research.

Bellemare, M. F., C. B. Barrett, and D. R. Just (2013): "The welfare impacts of commodity price volatility: evidence from rural Ethiopia," American Journal of Agricultural Economics, $95(4), 877-899$.

Bobenrieth, E., B. Bobenrieth, and D. Zeng (2013): "Stocks-to-use ratios and prices as indicators of vulnerability to spikes in global cereal markets," Agricultural Economics, 44, 1-10.

Bohl, M. T., and P. M. Stephan (2013): "Does futures speculation destabilize spot prices? New evidence for commodity markets," Journal of Agricultural and Applied Economics, 45(04), $595-616$.

Bollerslev, T. (1986): "Generalized autoregressive conditional heteroskedasticity," Journal of econometrics, 31(5), 307-327.

BRAndt, M. W., And C. S. Jones (2006): "Volatility forecasting with range-based EGARCH models," Journal of Business 83 Economic Statistics, 24(4), 470-486.

Bruno, V. G., B. Büyükşahin, And M. A. Robe (2016): "The financialization of food?," American Journal of Agricultural Economics, p. aaw059. 
Chen, C. W., R. Gerlach, and E. Lin (2008): "Volatility forecasting using threshold heteroskedastic models of the intra-day range," Computational Statistics \& Data Analysis, 52(6), $2990-3010$.

Cheng, I.-H., And W. XIong (2014): "Financialization of Commodity Markets," The Annual Review of Financial Economics, 6(1), 419-441.

Chkili, W., S. Hammoudeh, and D. K. NGuyen (2014): "Volatility forecasting and risk management for commodity markets in the presence of asymmetry and long memory," Energy Economics, $41,1-18$.

Chou, R. Y. (2005): "Forecasting financial volatilities with extreme values: the conditional autoregressive range (CARR) model," Journal of Money, Credit and Banking, 37(3), 561-582.

Clapp, J. (2009): "Food Price Volatility and Vulnerability in the Global South: considering the global economic context," Third World Quarterly, 30(6), 1183-1196.

Creti, A., M. Jö̈ts, and V. Mignon (2013): "On the links between stock and commodity markets' volatility," Energy Economics, 37, 16-28.

De Long, J. B., A. Shleifer, L. H. Summers, and R. J. Waldmann (1990): "Noise trader risk in financial markets," Journal of political Economy, pp. 703-738.

Easterbrook, F. H. (1986): "Monopoly, Manipulation, and the Regulation of Futures Markets," The Journal of Business, 59(2), 103-127.

Ederington, L., And J. H. LeE (2002): "Who trades futures and how: Evidence from the heating oil futures market," The Journal of Business, 75(2), 353-373.

ENGLE, R. F. (1982): "Autoregressive conditional heteroscedasticity with estimates of the variance of United Kingdom inflation," Econometrica, 50(4), 987-1007. 
- (2002): "Dynamic conditional correlation: A simple class of multivariate generalized autoregressive conditional heteroskedasticity models," Journal of Business 63 Economic Statistics, $20(3), 339-350$.

Federal Register (2011): Position Limits for Futures and Swaps; Final Rule and Interim Final Rule,Commodity Futures Trading Commission, FR Doc No: 2011-28809.

(2016): Position Limits for Derivatives; Proposed Rules,Commodity Futures Trading Commission, RIN 3038-AD99.

Friedman, M. (1953): "The case for flexible exchange rates," Essays in Positive Economics, University of Chicago Press.

Gilbert, C. L. (2012): "Speculative impacts on grains price volatility," in 123rd Seminar, February 23-24, 2012, Dublin, Ireland, no. 122540. European Association of Agricultural Economists.

Gilbert, C. L., And C. W. Morgan (2010): "Food price volatility," Philosophical Transactions of the Royal Society of London B: Biological Sciences, 365(1554), 3023-3034.

Gilbert, C. L., and S. Pfuderer (2014): "The role of index trading in price formation in the grains and oilseeds markets," Journal of Agricultural Economics, 65(2), 303-322.

Grosche, S.-C. (2014): "What Does Granger Causality Prove? A Critical Examination of the Interpretation of Granger Causality Results on Price Effects of Index Trading in Agricultural Commodity Markets," Journal of Agricultural Economics, 65(2), 279-302.

Gwilym, R., And M. S. Ebrahim (2013): “Can position limits restrain ŚrogueŠtrading?," Journal of Banking \& Finance, 37(3), 824-836.

HaAse, M., Y. S. Zimmermann, and H. Zimmermann (2016): "The impact of speculation 
on commodity futures markets-A review of the findings of 100 empirical studies," Journal of Commodity Markets, 3(1), 1-15.

Henderson, B. J., N. D. Pearson, and L. Wang (2015): "New evidence on the financialization of commodity markets," Review of Financial Studies, 28(5), 1285-1311.

Hernandez, M., and M. Torero (2010): "Examining the dynamic relationship between spot and future prices of agricultural commodities," .

Irwin, S. H., And D. R. SAnders (2011): "Index Funds, Financialization, and Commodity Futures Markets," Applied Economic Perspectives and Policy, 33(1), 1-31.

IRwin, S. H., AND D. R. SANDERs (2012): "Testing the Masters Hypothesis in commodity futures markets," Energy economics, 34(1), 256-269.

ISDA vs. CFTC (2012): "Civil Action No. 11-cv-2146 (RLW)," U.S. district court for the district of Columbia.

Ji, Q., AND Y. FAN (2012): "How does oil price volatility affect non-energy commodity markets?," Applied Energy, 89(1), 273-280.

Kim, A. (2015): "Does futures speculation destabilize commodity markets?," Journal of Futures Markets, 35(8), 696-714.

Luo, G. Y. (1998): "Market efficiency and natural selection in a commodity futures market," Review of Financial Studies, 11(3), 647-674.

Marshall, B. R., N. H. Nguyen, and N. Visaltanachoti (2011): "Commodity liquidity measurement and transaction costs," Review of Financial Studies, p. hhr075. 
Masters, M. W. (2008): "Testimony before the Committee on Homeland Security and Governmental Affairs. United States Senate, May 20, 2008," Internet access on November, 24, 2012.

Moschini, G., And R. J. Myers (2002): "Testing for constant hedge ratios in commodity markets: a multivariate GARCH approach," Journal of Empirical Finance, 9(5), 589-603.

Nazlioglu, S., C. Erdem, and U. Soytas (2013): "Volatility spillover between oil and agricultural commodity markets," Energy Economics, 36, 658-665.

PARkinson, M. (1980): "The extreme value method for estimating the variance of the rate of return," Journal of Business, 53(1), 61-65.

Pastor, L., and R. F. Stambaugh (2003): "Liquidity risk and price discovery," Journal of Political Economy, 111(3), 642-685.

RoAche, S. K. (2010): "What explains the rise in food price volatility?," IMF Working Papers, pp. $1-29$.

Samuelson, P. A. (1965): "Proof That Properly Anticipated Prices Fluctuate Randomly," Industrial Management Review, 6(2), 41-49.

SAnders, D. R., ANd S. H. IRWin (2010): "A speculative bubble in commodity futures prices? Cross-sectional evidence," Agricultural Economics, 41(1), 25-32.

(2011): "The impact of index funds in commodity futures markets: A systems approach," Journal of Alternative Investments, 14(1), 40-49.

Sanders, D. R., S. H. Irwin, and R. P. Merrin (2010): "The Adequacy of Speculation in Agricultural Futures Markets: Too Much of a Good Thing?," Applied Economic Perspectives and Policy, 32(1), 77-94. 
Shiller, R. J., S. Fischer, and B. M. Friedman (1984): "Stock prices and social dynamics," Brookings papers on economic activity, pp. 457-510.

Shleifer, A., And L. H. Summers (1990): "The noise trader approach to finance," The Journal of Economic Perspectives, pp. 19-33.

Silvennoinen, A., And S. Thorp (2013): "Financialization, crisis and commodity correlation dynamics," Journal of International Financial Markets, Institutions and Money, 24, 42-65.

Stoll, H. R., and R. E. Whaley (2010): "Commodity Index Investing and Commodity Futures Prices," Journal of Applied Finance, 20, 7-4b6.

United Nations (2015): Transforming our World: The 2030 agenda for global action United Nations.

Working, H. (1960): "Speculation on Hedging Markets," Food Research Institute Studies, 1, 185220.

Zeileis, A., C. Kleiber, W. Krämer, and K. Hornik (2003): "Testing and dating of structural changes in practice," Computational Statistics \& Data Analysis, 44(1), 109-123. 


\section{A Additional tables}

Table 7: Distributional Characteristics of Innovations in Excess Speculation

The table presents distributional characteristics of weekly innovations of the Working T-Index. Min and Max refer to the minimum and maximum observation. Std, Skew and Kurt denote the standard deviation, skewness and kurtosis, and $\rho_{1}$ and $\rho_{2}$ denote the coefficient of autocorrelation at lag 1 and $3 . \quad$ Asterisks ${ }^{* * *} /{ }^{* *} /{ }^{*}$ denote statistical significance at the $1 / 5 / 10 \%$ level.

\begin{tabular}{|c|c|c|c|c|c|c|c|c|c|}
\hline & Min & Median & Mean & $\operatorname{Max}$ & Std & Skew & Kurt & $\rho_{1}$ & $\rho_{3}$ \\
\hline \multicolumn{10}{|c|}{ Panel A1: 1995.03 - 2015.03 (COT Report) } \\
\hline Chicago & -0.139 & -0.001 & 0.000 & 0.135 & 0.024 & -0.019 & 8.899 & 0.01 & $-0.09^{* * *}$ \\
\hline Kansas & -0.135 & 0.001 & 0.000 & 0.121 & 0.022 & -0.313 & 9.870 & $-0.08^{* * *}$ & -0.04 \\
\hline Minneapolis & -0.180 & 0.000 & 0.000 & 0.123 & 0.021 & -0.513 & 16.848 & $-0.22^{* * *}$ & -0.05 \\
\hline \multicolumn{10}{|c|}{ Panel A2: 1995.03 - 2006.01 (COT Report) } \\
\hline Chicago & -0.139 & -0.001 & -0.000 & 0.135 & 0.030 & -0.062 & 6.835 & 0.03 & $-0.09^{* *}$ \\
\hline Kansas & -0.135 & 0.000 & -0.000 & 0.121 & 0.022 & -0.380 & 9.736 & $-0.21^{* * *}$ & $-0.13^{* *}$ \\
\hline Minneapolis & -0.180 & 0.000 & -0.000 & 0.121 & 0.024 & -0.622 & 14.909 & $-0.31^{* * *}$ & -0.06 \\
\hline \multicolumn{10}{|c|}{ Panel A3: 2006.01 - 2015.03 (COT Report) } \\
\hline Chicago & -0.056 & -0.000 & 0.000 & 0.076 & 0.016 & 0.457 & 6.680 & $-0.08^{*}$ & $-0.13^{* *}$ \\
\hline Kansas & -0.109 & 0.001 & 0.001 & 0.107 & 0.023 & -0.251 & 9.950 & 0.05 & 0.06 \\
\hline Minneapolis & -0.116 & 0.000 & 0.000 & 0.123 & 0.017 & -0.049 & 16.908 & 0 & -0.03 \\
\hline \multicolumn{10}{|c|}{ Panel B1: 2006.01 - 2015.03 (CIT Report) } \\
\hline Chicago & -0.296 & -0.001 & 0.001 & 0.235 & 0.041 & -0.701 & 12.382 & $0.21^{* * *}$ & -0.06 \\
\hline Kansas & -0.128 & 0.001 & 0.001 & 0.074 & 0.024 & -0.878 & 7.488 & $0.25^{* * *}$ & 0.02 \\
\hline \multicolumn{10}{|c|}{ Panel B2: 2006.01 - 2009.12 (CIT Report) } \\
\hline Chicago & -0.123 & -0.001 & 0.000 & 0.129 & 0.032 & 0.257 & 5.162 & $0.12^{*}$ & 0.02 \\
\hline Kansas & -0.099 & 0.001 & 0.001 & 0.059 & 0.019 & -1.233 & 8.204 & $0.15^{* *}$ & -0.01 \\
\hline \multicolumn{10}{|c|}{ Panel B3: 2010.01 - 2015.03 (CIT Report) } \\
\hline Chicago & -0.296 & -0.001 & 0.001 & 0.235 & 0.047 & -0.912 & 12.154 & $0.25^{* * *}$ & -0.08 \\
\hline Kansas & -0.128 & 0.001 & 0.001 & 0.074 & 0.028 & -0.755 & 6.505 & $0.29^{* * *}$ & 0.04 \\
\hline
\end{tabular}

\section{B Robustness}

In this section we test for the robustness of our results. Our first concern is that focusing on speculative activity as the only exogenous variable may not account for all omitted variable biases that might potentially affect our results. To address this concern, we consider the following modifications to our base model. First, we include monthly dummy variables to control for seasonal effects in volatility clustering. Second, we add a variable that reflects the contracts' time to expiration 
$(d 2 \exp )$ to control for the well-known Samuelson effect (Samuelson (1965)) ${ }^{37}$. Third, we augment the model by adding monthly forecasts of future wheat inventory levels (storage), provided by the U.S. Department of Agriculture (USDA). ${ }^{38}$ These extensions also somewhat relax our assumption that the process governing conditional volatilities is closely comparable across these five markets.

Table 8 shows that our results remain robust under all specifications considered. Controlling for seasonal effects slightly reduces the $\alpha$ in all the markets, suggesting that intra-season volatility clustering is higher (see Panel A1). Our core findings remain unaffected though. Again, the lowest shock amplification parameter is observed in Chicago $(\alpha=0.11)$, and the parameter increases across markets with a decreasing level of speculative activity. Importantly, the guilt parameter remains consistently negative and statistically significant. Likewise, results for the sub-periods remain qualitatively and quantitatively unchanged, although the guilt parameter is now significant for Minneapolis in the second sub-period (Panels B1 and C1; for the original estimates, see Table 4, Panels B and C). Controlling for time to expiration and inventory levels does not change our core findings for the investigated periods either (Panels A2, B2 and C2; for the original estimates, see Table 4).

Finally, although the focus of this paper is on international wheat markets, we also examine whether our results remain robust for other classes of agricultural commodities. Specifically, we analyse two soft commodities (coffee, $\mathrm{KC}$ and cacao, $\mathrm{CC}$ ) and one commodity from the livestock market (live cattle, LC) using the same investigation period and sub-periods. We focus on the guilt parameter since the shock amplification parameter is not immediately comparable across commodities.

Table 9 shows that our core results remain robust also for commodities other than wheat, see columns 2 to 4 . For all three commodities, the guilt parameter is negative with the exception of KC

\footnotetext{
${ }^{37}$ See, Moschini and Myers (2002) for addressing seasonality and time to maturity effects in a GARCH framework.

${ }^{38}$ See Bobenrieth, Bobenrieth, and Zeng (2013) or Bruno, Büyükşahin, and Robe (2016) for application of this variable.
} 
in the first sub-period. Further support is provided by comparing the shock amplification parameter over time: it is lower in the second sub-period. These findings are again robust to controlling for seasonal effects $(d m t h)$, see columns 5 to $7^{39}$.

\footnotetext{
${ }^{39}$ Parameter estimates for seasonal effects are not shown in the table.
} 
Table 8: Robustness of Volatility Dynamics

The table reports maximum likelihood estimates of a $\operatorname{CARRX}(1,1)$ model (equation 2) of weekly log-ranges for a cross section of nearby wheat futures. The models reported in Panels A1, B1 and C1 include the following exogenous variables: weekly innovations of the Working T-Index calculated from the COT report of the CFTC $\left(\delta_{C O T}^{W T}\right)$ and seasonal dummies (not shown here). The models reported in Panels A2, B2 and C2 additionally include the following exogenous variables: time to expiration $\left(\delta^{d 2 e x p}\right)$ and USDA forecast of wheat inventory levels $\delta^{\text {storage }}$.

\begin{tabular}{|c|c|c|c|c|c|c|}
\hline & Chicago & Kansas & Minneapolis & Chicago & Kansas & Minneapolis \\
\hline & \multicolumn{3}{|c|}{ Panel A1: 1995.03 - 2015.03 } & \multicolumn{3}{|c|}{ Panel A2: 1995.03 - 2015.03 } \\
\hline \multirow[t]{2}{*}{$\omega$} & $0.0014^{*}$ & $0.0018^{* *}$ & $0.0018^{* *}$ & 0.0013 & 0.0016 & 0.0000 \\
\hline & $(1.7202)$ & $(1.9971)$ & $(1.9844)$ & $(1.4533)$ & $(1.5504)$ & $(0.0186)$ \\
\hline \multirow[t]{2}{*}{$\alpha$} & $0.1142^{* * *}$ & $0.1735^{* * *}$ & $0.1651^{* * *}$ & $0.1078^{* * *}$ & $0.1710^{* * *}$ & $0.1585^{* * *}$ \\
\hline & $(6.0338)$ & $(7.5579)$ & $(7.1553)$ & $(5.6717)$ & $(7.4044)$ & $(7.1932)$ \\
\hline \multirow[t]{2}{*}{$\beta$} & $0.8699^{* * *}$ & $0.7947^{* * *}$ & $0.8059^{* * *}$ & $0.8769^{* * *}$ & $0.7959^{* * *}$ & $0.7882^{* * *}$ \\
\hline & $(38.9538)$ & $(27.7631)$ & $(27.9728)$ & $(39.3553)$ & $(27.5324)$ & $(27.1666)$ \\
\hline \multirow[t]{2}{*}{$\sigma$} & $0.3549^{* * *}$ & $0.3954^{* * *}$ & $0.4292^{* * *}$ & $0.3545^{* * *}$ & $0.3952^{* * *}$ & $0.4242^{* * *}$ \\
\hline & $(45.6764)$ & $(45.6756)$ & $(45.6763)$ & $(45.6759)$ & $(45.6778)$ & $(45.6773)$ \\
\hline \multirow[t]{2}{*}{$\delta_{C O T}^{W T}$} & $-0.1244^{* * *}$ & $-0.1124^{* * *}$ & -0.0770 & $-0.1269^{* * *}$ & $-0.1155^{* * *}$ & $-0.0949^{* *}$ \\
\hline & $(-3.4074)$ & $(-3.1575)$ & $(-1.6172)$ & $(-3.5132)$ & $(-3.2181)$ & $(-2.0149)$ \\
\hline \multirow[t]{2}{*}{$\delta^{d 2 \exp }$} & & & & 0.0054 & 0.0259 & $0.2038^{* * *}$ \\
\hline & & & & $(0.1465)$ & $(0.6256)$ & $(4.4603)$ \\
\hline \multirow[t]{2}{*}{$\delta^{\text {storage }}$} & & & & $-0.0134^{*}$ & -0.0133 & $-0.0351^{* *}$ \\
\hline & & & & $(-1.6550)$ & $(-1.0257)$ & $(-2.4286)$ \\
\hline \multirow[t]{2}{*}{ llik } & -2701.4363 & -2715.5310 & -2686.3498 & -2702.7658 & -2716.2174 & -2698.6492 \\
\hline & \multicolumn{3}{|c|}{ Panel B1: 1995.03 - 2006.01 } & \multicolumn{3}{|c|}{ Panel B2: 1995.03 - 2006.01 } \\
\hline \multirow[t]{2}{*}{$\omega$} & $0.0030^{*}$ & $0.0047^{* *}$ & 0.0019 & 0.0033 & $0.0059^{* *}$ & 0.0028 \\
\hline & $(1.6528)$ & $(2.2236)$ & $(1.5469)$ & $(1.6342)$ & $(2.1198)$ & $(1.2508)$ \\
\hline \multirow[t]{2}{*}{$\alpha$} & $0.1074^{* * *}$ & $0.1814^{* * *}$ & $0.1381^{* * *}$ & $0.1008^{* * *}$ & $0.1754^{* * *}$ & $0.1257^{* * *}$ \\
\hline & $(3.9486)$ & $(5.0542)$ & $(4.4437)$ & $(3.6990)$ & $(4.8246)$ & $(4.1245)$ \\
\hline \multirow[t]{2}{*}{$\beta$} & $0.8110^{* * *}$ & $0.6837^{* * *}$ & $0.8129^{* * *}$ & $0.8031^{* * *}$ & $0.6371^{* * *}$ & $0.7179^{* * *}$ \\
\hline & (15.2689) & $(9.6521)$ & $(17.2873)$ & (14.6484) & $(7.7143)$ & (10.7394) \\
\hline \multirow[t]{2}{*}{$\sigma$} & $0.3246^{* * *}$ & $0.3819^{* * *}$ & $0.4422^{* * *}$ & $0.3237^{* * *}$ & $0.3798^{* * *}$ & $0.4345^{* * *}$ \\
\hline & $(33.5570)$ & $(33.5606)$ & $(33.5633)$ & $(33.5567)$ & $(33.5594)$ & $(33.5619)$ \\
\hline \multirow[t]{2}{*}{$\delta_{C O T}^{W T}$} & $-0.1129^{* *}$ & -0.0833 & -0.0660 & $-0.1132^{* *}$ & -0.0732 & -0.1077 \\
\hline & $(-2.2601)$ & $(-1.1893)$ & $(-0.9823)$ & $(-2.2613)$ & $(-1.0364)$ & $(-1.5526)$ \\
\hline \multirow[t]{2}{*}{$\delta^{d 2 \exp }$} & & & & 0.0232 & 0.0587 & $0.1914^{* * *}$ \\
\hline & & & & $(0.4319)$ & $(0.8677)$ & $(2.9263)$ \\
\hline \multirow[t]{2}{*}{$\delta^{\text {storage }}$} & & & & -0.0266 & $-0.0698^{* *}$ & $-0.1023^{* * *}$ \\
\hline & & & & $(-1.5683)$ & $(-1.9748)$ & $(-2.6019)$ \\
\hline \multirow[t]{2}{*}{ llik } & -1535.6996 & -1527.0163 & -1513.9847 & -1537.2417 & -1530.1315 & -1524.0624 \\
\hline & \multicolumn{3}{|c|}{ Panel C1: $2006.01-2015.03$} & Panel & $1 \mathrm{C2}: 2006.01$ & - 2015.03 \\
\hline$\omega$ & 0.0016 & 0.0017 & 0.0023 & 0.0009 & 0.0012 & -0.0005 \\
\hline & $(1.3780)$ & $(1.3284)$ & $(1.4744)$ & $(0.8254)$ & $(0.8041)$ & $(-0.3185)$ \\
\hline$\alpha$ & $0.1060^{* * *}$ & $0.1645^{* * *}$ & $0.1746^{* * *}$ & $0.0847^{* * *}$ & $0.1538^{* * *}$ & $0.1654^{* * *}$ \\
\hline & $(4.4085)$ & $(5.3837)$ & $(5.0123)$ & $(3.6272)$ & $(4.8160)$ & $(4.8797)$ \\
\hline$\beta$ & $0.8835^{* * *}$ & $0.8218^{* * *}$ & $0.7894^{* * *}$ & $0.9071^{* * *}$ & $0.8341^{* * *}$ & $0.7964^{* * *}$ \\
\hline & $(34.1240)$ & $(24.5928)$ & (19.0356) & $(36.5617)$ & $(23.8830)$ & $(19.5642)$ \\
\hline$\sigma$ & $0.3792^{* * *}$ & $0.4013^{* * *}$ & $0.4042^{* * *}$ & $0.3776^{* * *}$ & $0.4007^{* * *}$ & $0.3999^{* * *}$ \\
\hline & $(30.9916)$ & $(30.9876)$ & $(30.9921)$ & $(30.9944)$ & $(30.9917)$ & $(30.9873)$ \\
\hline$\delta_{C O T}^{W T}$ & $-0.1837^{* * *}$ & $-0.1135^{* *}$ & $-0.1427^{* *}$ & $-0.1988^{* * *}$ & $-0.1115^{* * *}$ & $-0.1431^{* *}$ \\
\hline & $(-3.0885)$ & $(-2.5713)$ & $(-1.9761)$ & $(-3.4750)$ & $(-2.6052)$ & $(-2.0907)$ \\
\hline$\delta^{d 2 e x p}$ & & & & 0.0468 & 0.0394 & $0.2568^{* * *}$ \\
\hline & & & & $(0.6720)$ & $(0.5443)$ & $(3.2483)$ \\
\hline$\delta^{\text {storage }}$ & & & & $-0.0254^{* *}$ & -0.0212 & -0.0232 \\
\hline & & & & $(-2.2889)$ & $(-1.1510)$ & $(-1.0414)$ \\
\hline llik & -1184.4748 & -1200.9722 & -1184.4432 & -1186.6681 & -1201.6727 & -1189.6566 \\
\hline
\end{tabular}


Table 9: Robustness of Volatility Dynamics dWT (COT)

The table reports maximum likelihood estimates of a CARRX $(1,1)$ model (equation 2) of weekly log-ranges for a cross section of coffee (KC), cocoa (CC) and live cattle (LC) nearby futures. Panels A1, B1 and C1 include as exogenous variable the weekly innovations of the Working T-Index, calculated from the information contained in the COT report of the CFTC $\left(\delta_{C O T}^{W T}\right)$. Panels A2, B2 and C2 additionally include seasonal dummies (not shown here).

\begin{tabular}{|c|c|c|c|c|c|c|}
\hline & $\mathrm{KC}$ & $\mathrm{CC}$ & $\mathrm{LC}$ & $\mathrm{KC}$ & $\mathrm{CC}$ & $\mathrm{LC}$ \\
\hline & \multicolumn{3}{|c|}{ Panel A1: $1995.03-2015.03$} & \multicolumn{3}{|c|}{ Panel A2: 1995.03 - 2015.03 (dmth) } \\
\hline \multirow[t]{2}{*}{$\omega$} & $0.0057^{* * *}$ & $0.0010^{* *}$ & $0.0016^{* * *}$ & $0.0047^{* *}$ & $0.0039^{* * *}$ & $0.0016^{* *}$ \\
\hline & (3.1393) & $(2.5033)$ & $(3.8717)$ & $(2.3778)$ & $(3.8740)$ & $(2.3610)$ \\
\hline \multirow[t]{2}{*}{$\alpha$} & $0.1723^{* * *}$ & $0.1114^{* * *}$ & $0.1905^{* * *}$ & $0.1553^{* * *}$ & $0.1060^{* * *}$ & $0.1814^{* * *}$ \\
\hline & $(5.8847)$ & $(7.0010)$ & $(8.6985)$ & $(5.7844)$ & $(7.3472)$ & $(8.4863)$ \\
\hline \multirow[t]{2}{*}{$\beta$} & $0.7467^{* * *}$ & $0.8707^{* * *}$ & $0.7514^{* * *}$ & $0.7796^{* * *}$ & $0.8760^{* * *}$ & $0.7605^{* * *}$ \\
\hline & $(15.0817)$ & $(44.6370)$ & $(25.1401)$ & $(17.8492)$ & $(49.9250)$ & $(26.0394)$ \\
\hline \multirow[t]{2}{*}{$\sigma$} & $0.3988^{* * *}$ & $0.4032^{* * *}$ & $0.3923^{* * *}$ & $0.3953^{* * *}$ & $0.3972^{* * *}$ & $0.3893^{* * *}$ \\
\hline & $(45.6775)$ & $(45.6795)$ & $(45.6766)$ & $(45.6779)$ & $(45.6854)$ & $(45.6770)$ \\
\hline \multirow[t]{2}{*}{$\delta_{C O T}^{W T}$} & $-0.1876^{* * *}$ & $-0.1251^{* * *}$ & -0.0022 & $-0.1885^{* * *}$ & $-0.1318^{* * *}$ & -0.0080 \\
\hline & $(-2.7893)$ & $(-3.2206)$ & $(-0.0958)$ & $(-2.8487)$ & $(-3.4448)$ & $(-0.3465)$ \\
\hline \multirow[t]{2}{*}{ llik } & $-2346.4566-$ & -2577.6910 & -3317.5190 & $-2355.6256-$ & -2593.3034 & -3325.4959 \\
\hline & \multicolumn{3}{|c|}{ Panel B1: 1995.03 - 2006.01 } & \multicolumn{3}{|c|}{ Panel B2: 1995.03 - 2006.01 (dmth) } \\
\hline \multirow[t]{2}{*}{$\omega$} & $0.0235^{* * *}$ & $0.0013^{* *}$ & $0.0026^{* * *}$ & $0.0233^{* * *}$ & $0.0038^{* *}$ & $0.0023^{*}$ \\
\hline & $(3.3756)$ & $(2.0448)$ & $(3.1057)$ & $(3.0391)$ & $(2.4802)$ & $(1.8934)$ \\
\hline \multirow[t]{2}{*}{$\alpha$} & $0.2396^{* * *}$ & $0.1180^{* * *}$ & $0.2064^{* * *}$ & $0.2265^{* * *}$ & $0.1103^{* * *}$ & $0.2017^{* * *}$ \\
\hline & $(5.5467)$ & $(5.0097)$ & $(6.2960)$ & $(5.3110)$ & $(5.0064)$ & $(6.2298)$ \\
\hline \multirow[t]{2}{*}{$\beta$} & $0.4579^{* * *}$ & $0.8585^{* * *}$ & $0.7059^{* * *}$ & $0.4921^{* * *}$ & $0.8685^{* * *}$ & $0.7060^{* * *}$ \\
\hline & $(3.9636)$ & $(28.5080)$ & $(14.2814)$ & $(4.3748)$ & $(31.0940)$ & $(14.2423)$ \\
\hline \multirow[t]{2}{*}{$\sigma$} & $0.4061^{* * *}$ & $0.4118^{* * *}$ & $0.4205^{* * *}$ & $0.4034^{* * *}$ & $0.4076^{* * *}$ & $0.4166^{* * *}$ \\
\hline & $(33.5585)$ & $(33.5671)$ & $(33.5568)$ & $(33.5592)$ & $(33.5695)$ & $(33.5606)$ \\
\hline \multirow[t]{2}{*}{$\delta_{C O T}^{W T}$} & 0.0813 & $-0.1819^{* * *}$ & -0.0103 & 0.0785 & $-0.1633^{* *}$ & -0.0186 \\
\hline & $(0.6568)$ & $(-2.7441)$ & $(-0.2829)$ & $(0.6326)$ & $(-2.4180)$ & $(-0.4964)$ \\
\hline \multirow[t]{2}{*}{ llik } & $-1198.1447-$ & -1374.5758 & -1735.6211 & -1201.9288 & -1380.2327 & -1740.7418 \\
\hline & \multicolumn{3}{|c|}{ Panel C1: 2006.01 - 2015.03 } & \multicolumn{3}{|c|}{ Panel C2: 2006.01 - 2015.03 (dmth) } \\
\hline \multirow[t]{2}{*}{$\omega$} & $0.0051^{* *}$ & 0.0006 & $0.0008^{* *}$ & $0.0037^{*}$ & $0.0039^{* * *}$ & 0.0009 \\
\hline & $(2.5642)$ & $(1.3262)$ & $(2.1078)$ & $(1.8593)$ & $(2.9783)$ & $(1.3986)$ \\
\hline \multirow[t]{2}{*}{$\alpha$} & $0.1525^{* * *}$ & $0.1026^{* * *}$ & $0.1662^{* * *}$ & $0.1276^{* * *}$ & $0.0969^{* * *}$ & $0.1457^{* * *}$ \\
\hline & $(4.5960)$ & $(5.0500)$ & $(6.0047)$ & $(4.3808)$ & $(5.4336)$ & $(5.8947)$ \\
\hline \multirow[t]{2}{*}{$\beta$} & $0.7646^{* * *}$ & $0.8862^{* * *}$ & $0.8043^{* * *}$ & $0.8079^{* * *}$ & $0.8898^{* * *}$ & $0.8260^{* * *}$ \\
\hline & $(13.6772)$ & $(37.3618)$ & $(23.7181)$ & $(17.3482)$ & $(42.7480)$ & $(27.6131)$ \\
\hline \multirow[t]{2}{*}{$\sigma$} & $0.3728^{* * *}$ & $0.3926^{* * *}$ & $0.3547^{* * *}$ & $0.3660^{* * *}$ & $0.3815^{* * *}$ & $0.3484^{* * *}$ \\
\hline & $(30.9877)$ & (30.9960) & $(30.9865)$ & $(30.9893)$ & $(30.9975)$ & $(30.9911)$ \\
\hline \multirow[t]{2}{*}{$\delta_{C O T}^{W T}$} & $-0.3287^{* * *}$ & $-0.0801^{*}$ & -0.0086 & $-0.3166^{* * *}$ & ${ }^{*}-0.1004^{* *}$ & -0.0094 \\
\hline & $(-5.0248)$ & $(-1.8686)$ & $(-0.3015)$ & $(-5.0150)$ & $(-2.2780)$ & $(-0.3372)$ \\
\hline llik & $-1169.8430-$ & -1204.3965 & -1591.5045 & -1178.6261 & -1218.3654 & -1600.0659 \\
\hline
\end{tabular}




\section{Position limits}

Speculative position limits are imposed by regulators (federal position limits) "in order to prevent excessive speculation and manipulation while ensuring sufficient market liquidity for bona fide hedgers and protecting the price discovery process." ${ }^{40}$ These limits define the maximum number of contracts that a person may hold or control for the purchase or sale of a commodity for future delivery or, on a futures equivalent basis. While these limits are strictly binding for speculators, hedgers may obtain an exemption from position limits, if they trade in accordance with the bona fide hedge requirements. The CFTC applies different limits for spot months, i.e. the contract next to expire, a single month and all-months combined. ${ }^{41}$ Typically, position limits are set at a lower level for spot months with physical delivery than for other months. The rationale behind this procedure is that contracts are vulnerable to manipulative practices during physical delivery, which causes large price fluctuations, especially when the underlying physical supply or demand is limited. The prevention of manipulative practices was the most important incentive to impose position limits, for both regulators and exchanges.

Prior to regulators, exchanges have established their own "position accountability levels" which are a tool, used to monitor their own trading venue in order to protect themselves against the risk of exercise of market power by holding or trading a dominate position, see Easterbrook (1986) or Gwilym and Ebrahim (2013). However, the imposition of position accountability levels are not based on a voluntary basis, rather, exchanges shall impose their own position limits for designated contracts for which no regulatory position limit exists and the concrete form of position accountability must comply with the CFTC regulation. ${ }^{42}$

\footnotetext{
${ }^{40}$ CFTC Q \& A - Position Limits for Derivatives, Division of Market Oversight 202-418-5260

${ }^{41}$ See, CFTC, Commodity and Securities Exchanges Part 150.1 to 150.3

${ }^{42}$ See, CFTC, Commodity and Securities Exchanges Part 150.5
} 